\title{
Optimization of Construction Parameters and Deformation Characteristics of Large-Section Loess Tunnel: A Case Study from Xi'an Metro
}

\author{
Mingji Zhao $\mathbb{D}^{1}$, Yun Cheng $\mathbb{D},^{2,3}$ Zhanping Song $\mathbb{D}^{2,3}$ Tong Wang $\mathbb{D}^{2,3}$ Yuwei Zhang, ${ }^{2,3}$ \\ and Baichao Liulian ${ }^{2,3}$ \\ ${ }^{1}$ School of Mechanical and Electrical Engineering, Xi'an University of Architecture and Technology, Xi'an 710055, China \\ ${ }^{2}$ School of Civil Engineering, Xi'an University of Architecture and Technology, Xi'an 710055, China \\ ${ }^{3}$ Shaanxi Key Laboratory of Geotechnical and Underground Space Engineering, Xi'an 710055, China
}

Correspondence should be addressed to Yun Cheng; chengyun_ifu@163.com and Zhanping Song; songzhpyt@xauat.edu.cn

Received 27 October 2020; Revised 14 December 2020; Accepted 24 December 2020; Published 1 March 2021

Academic Editor: Song-He Wang

Copyright (C) 2021 Mingji Zhao et al. This is an open access article distributed under the Creative Commons Attribution License, which permits unrestricted use, distribution, and reproduction in any medium, provided the original work is properly cited.

\begin{abstract}
Loess geological tunnels are characterized by weak geological structure and poor self-stability of surrounding rock, so effectively controlling the excavation face distances of different caverns is of great significance for guiding the safe construction of large-section tunnels. Based on the excavation of large-section loess tunnel from Xi'an Metro Line 4, the optimal excavation face distance is determined based on Midas numerical model. Then, the surface settlement and horizontal deformation are analyzed based on monitoring data, and, finally, the rationality of excavation face distance is verified. The results show that the influence of excavation face distance on surface settlement, vault settlement, and horizontal deformation is consistent. The surface settlement mainly occurs in the range of $-20 \sim 20 \mathrm{~m}$ from the tunnel centerline and the settlement trough formed has asymmetric characteristics. The vault settlement and horizontal deformation undergo first a rapid settlement and then a slow settlement. The connection between initial support and middle partition is mainly tensile stress and the middle and bottom parts of the supporting structure are mainly compressive stress. Numerical results suggest that the optimal excavation faces distance of $L_{1}, L_{2}$, and $L_{3}$ which can be 4,9 , and $9 \mathrm{~m}$, respectively. Construction monitoring data show that the double-sides heading method has a significant effect on surface settlement, vault settlement, and horizontal deformation. The surface settlement occurs within the range of $-17 \sim 6 \mathrm{~m}$ from the tunnel centerline. The maximum vault settlement and horizontal deformation are $73.00 \%$ and $65.50 \%$ of the maximum allowable. It can be seen that the actual excavation parameters optimized by Midas numerical model have high reliability.
\end{abstract}

\section{Introduction}

With the rapid development of urban traffic engineering, subway construction project has become an important symbol of urban construction and development speed $[1,2]$. However, due to the influence of ground buildings and underground complex traffic network, how to excavate the large-span and neighborhood tunnel safely and reasonably has become a problem that must be considered in underground space engineering. Xi'an, as the largest western central city in China, has a total population of about 10 million; the underground traffic construction has made rapid development in recent years. Loess geology is widely distributed in Xi'an area of China, which leads to the problems of shallow-buried structure, weak geology, poor self-stability of surrounding rocks, low bearing capacity, and fast deformation of tunnels in this area $[1,3,4]$.

The history of building structures in loess strata has been developed for thousands of years in China, but the construction of subway tunnels in loess areas began in the early 1960s [3-7]. For the large-section span tunnel, the doublesides heading method is widely used at home and abroad. Although the tunnel excavation method can effectively control the deformation of surrounding rock, the excavation section is divided into multiple blocks, the disturbance times to surrounding rock are increased, and the initial support 
structure is closed for a long time, which makes the construction period longer [8-12]. In this case, the convergence and deformation constraint ability of the surrounding rock is poor, which is not conducive to the excavation of the rear tunnel and the stability of the middle rock column. Moreover, the influence of construction parameters on construction mechanical behavior in parallel tunnel excavation is rare. Wang et al. [13] pointed out that the tensile and shear strength of tunnel support structure can be improved by laying steel mesh in the initial support process of the tunnel in loess area, so as to ensure the stability of the tunnel during construction. Based on the comprehensive consideration of many factors affecting the formation pressure of the loess tunnel, Niu et al. [14] put forward the empirical formula of formation pressure of loess tunnel by collecting the formation pressure of loess tunnel and the pressure value between soil and supporting structure. Guo [15] combined the special properties of loess strata to calculate and analyze the pressure of rock and soil during tunnel excavation and explained the reasons for the surface uplift and the final subsidence during the loess tunnel excavation. Liu et al. [16] studied the stress and deformation law of soil and supporting structure in loess double-arch tunnel using the numerical software. Zhong et al. [17] put forward the reasonable length of the double-arch tunnel in the loess area through numerical simulation and theoretical research. Gou and Zhang [18] used the analysis software to carry on the numerical simulation to the loess tunnel excavation and obtained the limit displacement value of instability failure in the loess tunnel. In the field measurement, some scholars had systematically studied the distribution law of neighborhood tunnel and systematically summarized the engineering monitoring data [19-21].

Moreover, Ghaboussi and Ranken [22] established a large number of experimental models to study the deformation development of surrounding rock and supporting structure during the excavation of the neighborhood tunnel. $\mathrm{Ng}$ et al. [23] studied the stress change law of rock column and soil in the tunnel by three-dimensional finite element model system and analyzed the influence of excavation faces distance on the stability of middle rock column. Park and Adachi [24], Lee and Rowe [25], and Chu et al. [26] analyzed the stress distribution characteristics during neighborhood tunnel excavation by two-dimensional strain. Suwansawat and Einstein [27] used the superposition method to predict the surface subsidence caused by the excavation of the double-hole parallel tunnel. Shirlaw et al. [28] measured the surface settlement of a Singapore double-hole tunnel subway; it is concluded that the settlement trough after the tunnel excavation is asymmetrical. Cording [29] monitored the surface settlement data of a double-hole tunnel subway in Washington and found that the asymmetric settlement trough on the surface after the completion of subsequent tunnel excavation was related to the excavation effect of the previous tunnel. According to the above analysis, because the urban subway tunnel is subjected to complex underground traffic network and buildings [30-33], the tunnel excavation process only depends on construction experience and later monitoring data to ensure the construction safety and tunnel stability have certain blindness. Therefore, it is of great significance to effectively control the excavation spacing of different caverns to guide the safe construction of large-section and neighborhood tunnels. However, there is little research on the optimization of parallel tunnel construction parameters $[4,34-36]$.

The tunnel section between Yannan $4^{\text {th }}$ Road Station and Datang Furong Garden Station of Xi'an Metro Line 4 belongs to an asymmetric, shallow-buried deep, largesection, and neighborhood tunnel, which intensifies the difficulty of tunnel construction, so it is important to select a reasonable excavation mode, excavation sequence, and construction parameters. Based on the geological data, this paper first simulates the excavation process of different caverns under different excavation face distances based on the Midas/NX 3D numerical model and analyzes the surface settlement, vault settlement, horizontal deformation law, and the deformation characteristics of supporting structure. Then, the optimal excavation face distances are determined based on the numerical simulation results. Finally, characteristics of surface settlement, vault settlement, and horizontal deformation of tunnel are analyzed based on the actual monitoring data in the construction process using double-sides heading method, the rationality of actual excavation parameters optimized is verified, and the research results have a reference significance for the prediction of settlement and deformation of tunnel surrounding rock.

\section{Engineering Overview}

2.1. Engineering Background. Xi' an Metro Line 4 is the major transportation routes in the north-south direction of Xi'an rail transit network, starting from Space Industry Base and ending at Caotan. Xi'an Metro Line 4 has a total length of $34.30 \mathrm{~km}$ and there are 28 stations. The route has successively passed 4 administrative districts, including Yanta District, Beilin District, Xincheng District, and Weiyang District of Xi'an City, and connects to 3 development zones including the Aerospace Industry Base, Qujiang New District, and Economic Development Zone.

The study section from Yannan 4th Road Station to Datang Furongyuan Garden Station, as shown in Figure 1(a), has a starting and ending mileage of CK8 $+371.825 \sim \mathrm{CK} 9+619.325$, with a total length of about $1.25 \mathrm{~km}$. The study tunnel section is mainly arranged underground along Furong West Road. The deepest buried depth of the tunnel vault is about $23.00 \mathrm{~m}$, and the section size is $12.13 \mathrm{~m} \times 10.03 \mathrm{~m}$ in a horseshoe shape.

2.2. Geological Characteristics. A geological survey shows that the ground of the tunnel construction site is relatively flat, and the ground elevation is between 442.16 and $446.50 \mathrm{~m}$. The geomorphic unit belongs to the fifth and sixth level terraces. The soil layers in the construction area are miscellaneous soil-filling, new loess, and old loess from the ground surface; the corresponding soil layer thicknesses are $1.50,10.60$, and $42.90 \mathrm{~m}$, respectively. 


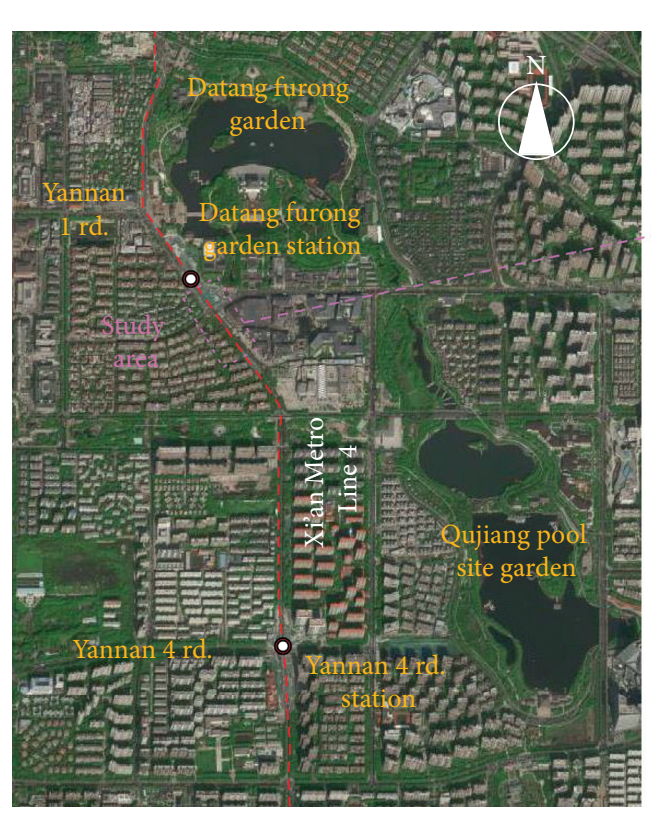

(a)

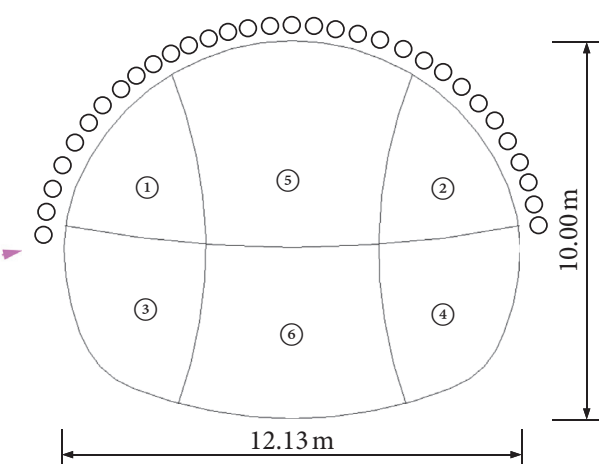

(b)

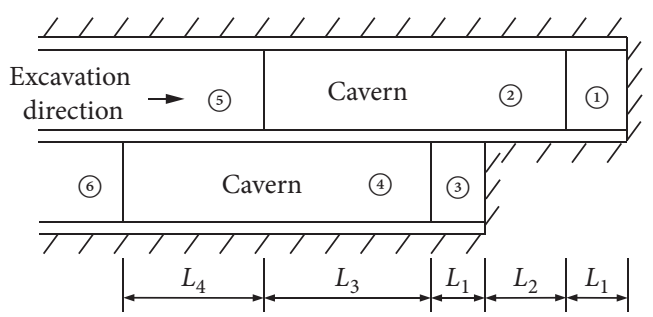

(c)

Figure 1: Xi'an Metro Line 4 and double-sides heading method. (a) Direction of Xi'an Metro Line 4. (b) Subsection construction process of double-sides heading method. (c) Construction sequence of the longitudinal section of tunnel excavation.

The construction site along the study section from Yannan 4th Road Station to Datang Furongyuan Garden Station is a self-gravity collapsible loess site (distributed thickly in the east and thin in the west), and the remaining north and south ends are nonweight collapsible loess sites. According to the buried depth of the existing tunnel floor, it can be known that the foundation of the main line tunnel structure of the section is a noncollapsible foundation. The study area has good hydrology and geology, and there is no surface water near the stratum. The quaternary pore water in the scope of project construction has little impact on construction [37].

\subsection{Establishment of Numerical Model and Excavation Scheme}

2.3.1. Numerical Models and Parameters. Assuming that the ground and each soil layer are homogeneous and horizontally distributed, the rock and soil mass adopts the Mohr-Column constitutive model, and the supporting structure and large-section partition wall are assumed to be deformable elastic plate elements. The pipe roof above the large-section vault is simulated by changing the elements properties. The material parameters of the model are the same as those of actual engineering geological materials, as shown in Table 1 where $D$ is density, $E$ is elastic modulus, $\gamma$ is Poisson's ratio, $\varphi$ is friction angle, $C$ is cohesive strength, and $T$ is thickness.

According to the elasticity theory and rock mechanics theory $[27,28,31]$, the influence area of tunnel excavation on the stress state of surrounding rock is 3 times the width of the tunnel outside the tunnel excavation outline. The horizontal direction ( $x$-axis) of the built numerical model is about $105 \mathrm{~m}$, along the tunnel axis direction ( $y$-axis) of about
$155 \mathrm{~m}$, and vertical direction ( $z$-axis) is the distance from the bottom of the large-section tunnel to the lower boundary as $55 \mathrm{~m}$. The numerical model is divided into 142800 units, including 25000 nodes, as shown in Figure 2. When performing the numerical calculations under static conditions, only the influence of tunnel excavation on the soil and supporting structure under the weight condition needs to be considered, and the influence of tectonic stress and groundwater environment is ignored. Therefore, the surrounding boundary of the numerical model is horizontal restraint, and the boundary is set to horizontal and vertical restraints.

\subsubsection{Construction Scheme of the Double-Sides Heading} Method. To overcome the poor self-stabilization ability of surrounding rock of loess tunnel, the double-sides heading method is often used to divide the large-section cavern into multiple excavation sections for construction $[3,14,15]$. Too long or too short distance (excavation face distance) between multisection excavated caverns is not conducive to the stability of surrounding rock, so how to determine a reasonable distance between excavation caverns is a problem that needs comprehensive consideration when large-section excavation is carried out in loess strata $[14,38]$. Therefore, optimizing the excavation face distances of the double-sides heading method and analyzing the deformation characteristics are the key issues in the tunnel construction of this project.

In the calculation of model excavation, the initial supporting structure is implemented one construction step later. Since the secondary liner is constructed after the tunnel section is stabilized, it is far from the excavation face, so the three-dimensional model calculation process is not applied. The subsection construction process of the double-sides 
TABle 1: Physical and mechanical parameters of materials.

\begin{tabular}{|c|c|c|c|c|c|c|}
\hline Materials & $D\left(\mathrm{kN} / \mathrm{m}^{3}\right)$ & $E(\mathrm{MPa})$ & $\gamma$ & $\varphi\left(^{\circ}\right)$ & $C(\mathrm{kPa})$ & $T(\mathrm{~m})$ \\
\hline Miscellaneous soil-filling & 18 & 2 & 0.25 & 36 & 15 & 1.50 \\
\hline New loess & 18.50 & 50 & 0.20 & 22.50 & 25 & 10.60 \\
\hline Old loess 1 & 19.60 & 160 & 0.20 & 22.50 & 32 & 20 \\
\hline Old loess 2 & 19.60 & 160 & 0.20 & 22.50 & 32 & 22.90 \\
\hline Pipe roof & 25 & 50000 & 0.30 & - & - & - \\
\hline Primary supporting & 23 & 21000 & 0.20 & - & - & - \\
\hline Middle partition & 25 & 27000 & 0.20 & - & - & - \\
\hline Second liner & 25 & 29000 & 0.20 & - & - & - \\
\hline
\end{tabular}

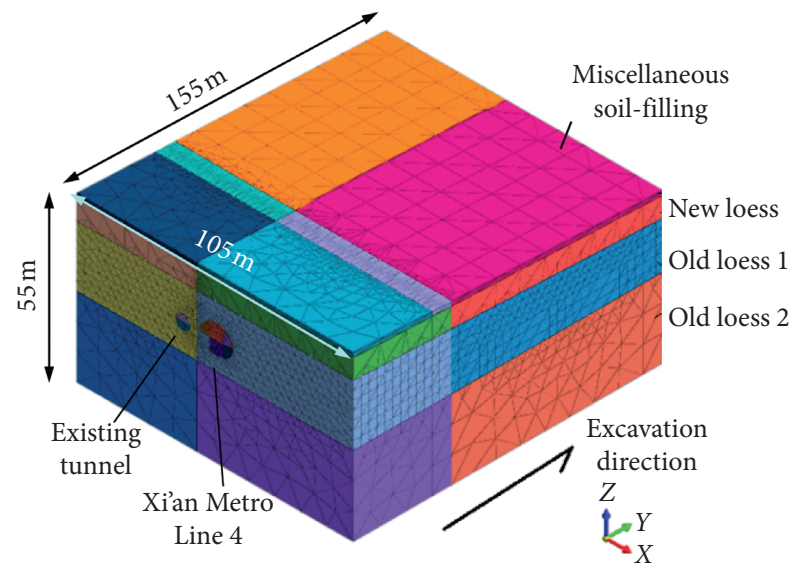

FIgURE 2: Model size and soil layer distribution.

heading method and construction sequence of the longitudinal section of tunnel excavation are shown in Figures 1(b) and 1(c), respectively. The excavation face distance $L_{1}$ of caverns (1) (2) and caverns (3) (4) is 0,2 $(0.5 D), 4(1 D), 9(2 D)$, and $13 \mathrm{~m}(3 D)$; excavation face distance $L_{2}$ of caverns (2) (3) is $0(0 D), 4(1 D), 9(2 D), 13$ $(3 D)$, and $21 \mathrm{~m}(5 D)$; and excavation face distance $L_{3}$ of caverns (4) (5) is $4(1 D), 9(2 D), 13(3 D)$, and $21 \mathrm{~m}(5 D) . D$ is the diameter of excavation cavern. The selection and discussion of optimal excavation face distance will be carried out in the next sections.

\section{Optimization and Analysis of Construction Parameters}

To accurately determine the influence of excavation face distance of each cavern on the settlement characteristics of ground surface and vault, only one excavation face distance change is considered in each calculation, and then the optimal excavation face distance between each cavern is calculated in turn according to the construction and excavation sequence. Then, based on the excavation scheme as shown in Figure 1(c) and the numerical model as shown in Figure 2, The influence of excavation face distances $L_{1}(0.5 D, 1 D, 2 D, 3 D), L_{2}(0 D, 1 D, 2 D, 3 D, 5 D)$, and $L_{3}$ $(1 D, 2 D, 3 D, 5 D)$ on the surface settlement and vault settlement and horizontal convergence characteristics and distribution characteristics of principal stress of supporting structure are studied in the following sections.

It should be pointed out that since the excavation face distance between caverns (3) and (4) is equal to the distance between caverns (1) and (2), only the influence of excavation face distance between caverns (1) and (2) on the characteristics of surface settlement, vault settlement, and horizontal deformation is discussed in this article. Besides, due to the excavation face distance between caverns (5) and (6) being equal to the distance between caverns (1) and (2), this article also does not discuss the influence of excavation face distance $\left(L_{4}\right)$ on the surface settlement, vault settlement, and horizontal deformation of this tunnel.

\subsection{Influence of Excavation Face Distance $L_{1}$ on Tunnel Stability}

3.1.1. Surface Settlement Characteristics. Figure 3 shows the surface settlement characteristics of CK9 + 462 section after the excavation of cavern (1) and cavern (2), with an excavation face distance of $0,2,4,9$, and $13 \mathrm{~m}$, respectively. The longitudinal dashed line in Figure 3(a) is the tunnel centerline. It can be seen from Figure 3(a) that surface settlement curves with different excavation face distances have a similar development trend, the surface settlement is $4 \sim 14.36 \mathrm{~mm}$ within the range of $-20 \sim 20 \mathrm{~m}$ from the tunnel centerline, and the surface settlement on the left and right sides is $0 \sim 4 \mathrm{~mm}$. It can be seen that at the same measuring points, the surface settlement on the right side is significantly greater than that on the left side, and the maximum surface settlement is located in the soil at the upper right of the tunnel vault. This results in a "single-peak" V-shaped distribution of surface settlement curve, and the formed settlement trough is asymmetric about the tunnel centerline, which is similar to the surface settlement law of a doublehole tunnel subway in Singapore [28].

Figure 3(b) shows the relationship between maximum vault settlement, surface settlement in tunnel centerline, and excavation face distance $\left(L_{1}\right)$, respectively. It can be seen from Figure 3(a) that the maximum vault settlement is 14.36 when the excavation face distance $\left(L_{1}\right)$ of caverns (1) and (2) is $0 \mathrm{~m}$. And the minimum vault settlement is $13.97 \mathrm{~mm}$ when the excavation face distance $\left(L_{1}\right)$ is $16 \mathrm{~m}$, which is $2.72 \%$ lower than the former settlement. In addition, the surface settlements in tunnel centerline under different excavation face distances are 13.04, 12.92, 12.82, 12.76, and $12.71 \mathrm{~mm}$, respectively. The decrease in the settlement is not obvious, and its decrease is not proportional to the increase in $L_{1}$. It can be seen that the maximum settlement of tunnel vault and surface settlement of tunnel centerline both decrease gradually with increasing excavation face distance $L_{1}$, while the reduction is not significant. 


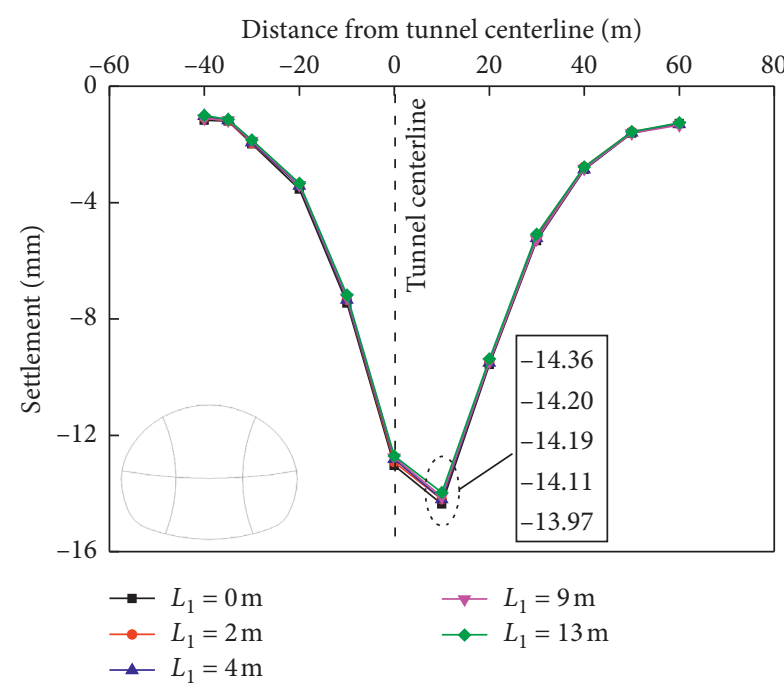

(a)

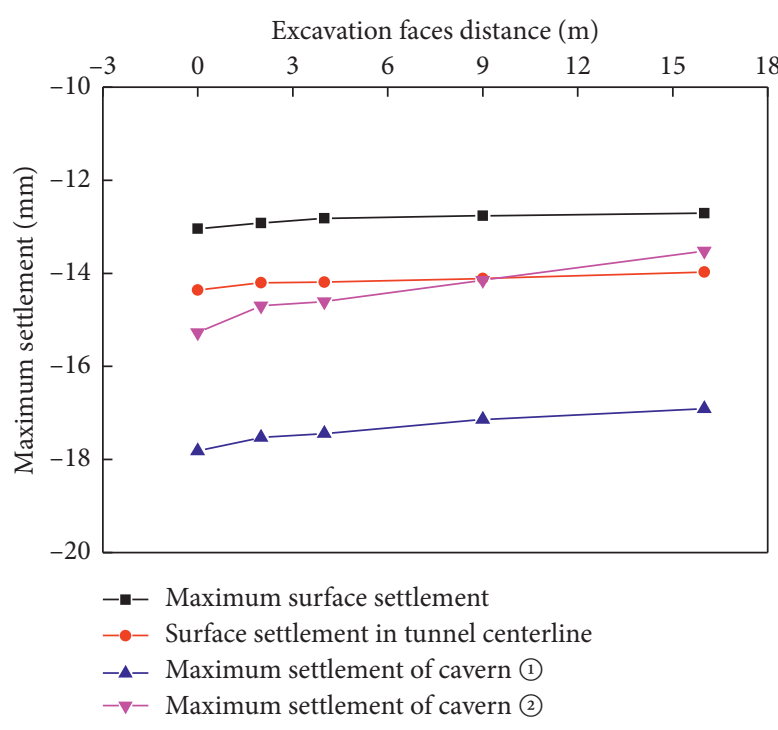

(b)

Figure 3: Surface settlement characteristics of CK9 + 462 section. (a) Surface settlement curve. (b) Relationship between maximum vault settlement, surface settlement, and excavation face distance $\left(L_{1}\right)$.

3.1.2. Vault Settlement Characteristics of Caverns (1) and (2). Taking the vault settlement at CK9 + 462 section as the research object, Figure 4 shows the vault settlement curve of cavern (1) and vault settlement curve of cavern (2). It can be seen from Figure 4 that vault settlement curves at different excavation face distances have the same development trend with increasing excavation steps, and all the settlement curves have experienced first a rapid settlement and then a slow settlement. The two-stage boundary points of the settlement curves of caverns (1) and (2) are 15 and $12 \mathrm{~mm}$, respectively, and the corresponding excavation step ranges are 16 20 steps and 14 20 steps. This indicates that the settlement deformation of cavern (2) is gradually stable than that of cavern (1).

It can also be seen from Figure 4 that when the excavation face reaches the characteristic section, the tunnel vault will produce large settlement deformation, and then the deformation will continue to grow, but the growth trend will gradually slow and eventually stabilize. As can be seen, the excavation face distance $\left(L_{1}\right)$ has similar effects on the vault settlement and surface settlement at the characteristic section. With increasing excavation face distance $\left(L_{1}\right)$, the maximum settlement of tunnel vault gradually decreases, and the decrease is not proportional to the increase in the excavation face distance $\left(L_{1}\right)$, as shown in Figure 3(b). The analysis data shows that when the excavation face distance $\left(L_{1}\right)$ increases from 0 to $16 \mathrm{~m}$, the vault settlement of cavern (1) changes from 17.82 to $16.91 \mathrm{~mm}$, which reduces by $5.11 \%$, and the vault settlement of cavern (2) changes from 15.27 to $13.52 \mathrm{~mm}$ with a decrease of $11.46 \%$, indicating that the increased excavation face distance $\left(L_{1}\right)$ has a more obvious impact on the vault settlement of cave (2) than that of cave (1).

3.1.3. Horizontal Deformation Characteristics of Caverns (1) and (2). Figure 5 shows the development trend of horizontal deformation of caverns (1) and (2) with increasing construction step, respectively. The deformation curves are similar to the change trend of vault settlement, and it has generally experienced a rapid deformation stage and a deformation convergence stage. The rapid deformation of tunnel cavity mainly occurs at the completion stage; its deformation rate decreases significantly with the construction of supporting structure, gradually undergoes transitional deformation, and then enters the convergence deformation stage; and, finally, the cumulative deformation of caverns (1) and (2) tends to stabilize.

There is a significant turning point in the horizontal deformation curves of caverns (1) and (2). Figure 5 shows that the turning points of horizontal deformation curves are roughly the 14th excavation step, and corresponding horizontal deformations of cavern (1) are 6.33, 5.72, 5.21, 5.18, and $5.09 \mathrm{~mm}$, and the corresponding horizontal deformations of cavern (2) are 3.96, 3.83, 3.66, 3.59, and $3.57 \mathrm{~mm}$, respectively. It can be seen that the convergence value of horizontal deformation of caverns (1) and (2) at the turning point gradually decreases with increasing excavation face distance.

Figure 5(c) shows the change trend of convergence value of horizontal deformation curves of caverns (1) and (2) in the convergence stage. It can be seen from Figure 5(b) that the horizontal convergence value of cavern (2) gradually decreases with increasing excavation face distance when the length of excavation face $L_{1}$ is $0 \sim 4 \mathrm{~m}$. However, the convergence value of horizontal deformation has an increase tendency when the excavation face distance $L 1$ is greater than $4 \mathrm{~m}$. The above analysis shows that excavation face distance $L_{1}=4 \mathrm{~m}$ is the turning point of convergence value of horizontal deformation of caverns (1) and (2). Therefore, horizontal deformation and stability of tunnel can be well controlled when the excavation face distance $\left(L_{1}\right)$ is $4 \mathrm{~m}$.

3.1.4. Principal Stress Characteristics of Supporting Structure of Caverns (1) and (2). Figures 6(a)-6(e) show the principal 


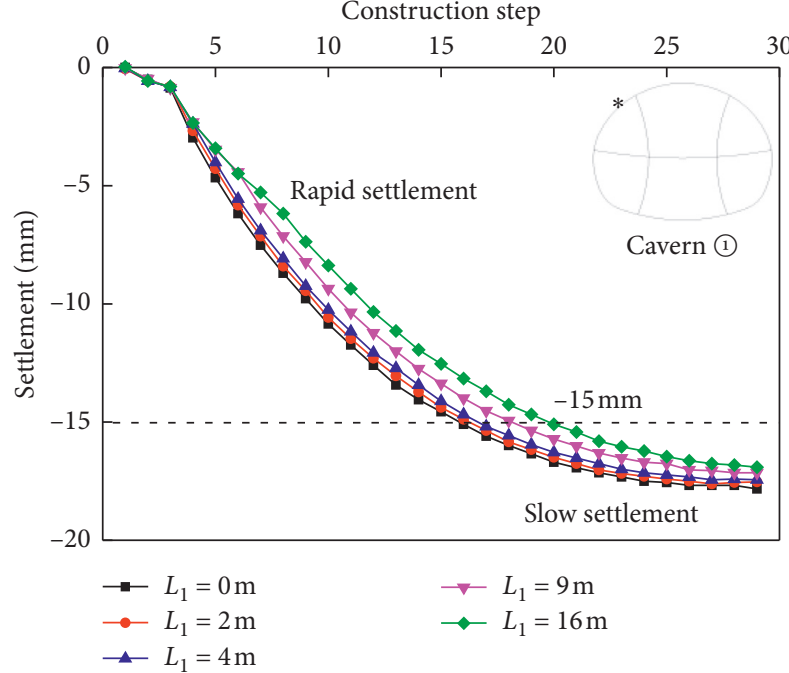

(a)

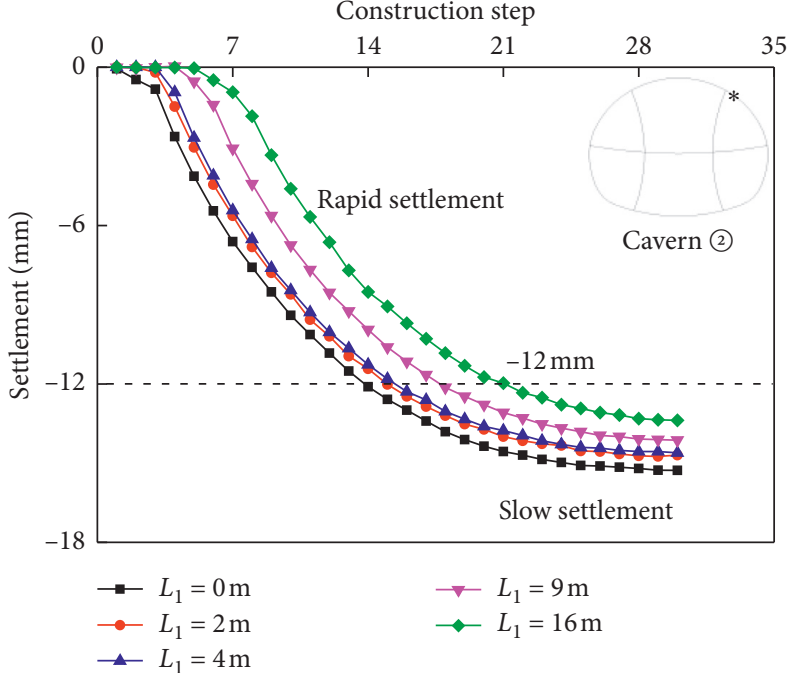

(b)

FIGURE 4: Vault settlement characteristics of CK9 + 462 section. (a) Vault settlement curve of cavern (1). (b) Vault settlement curve of cavern (2).

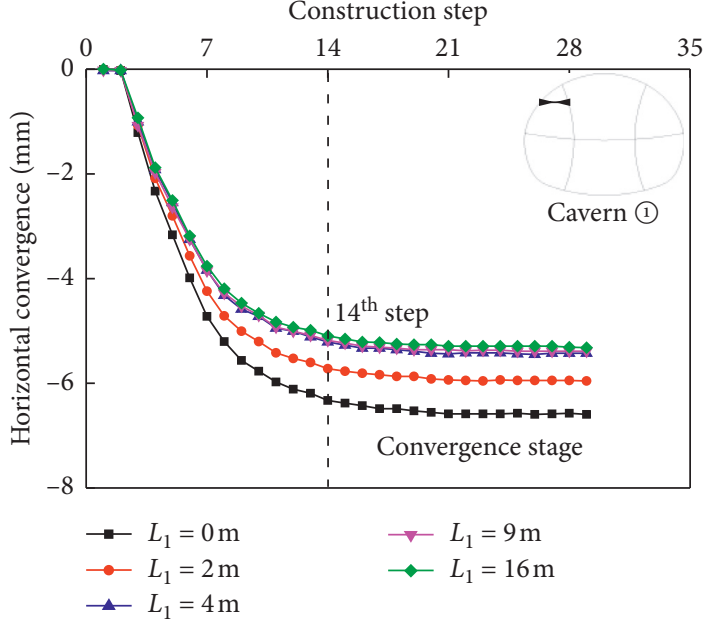

(a)

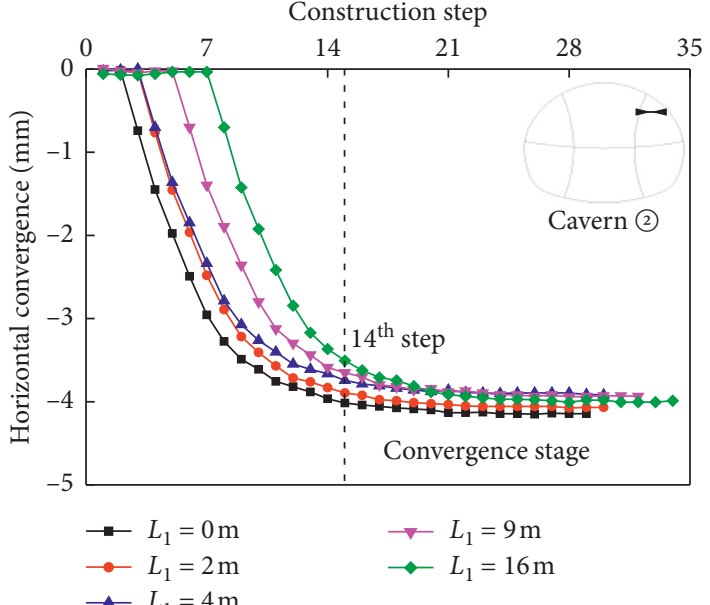

(b)

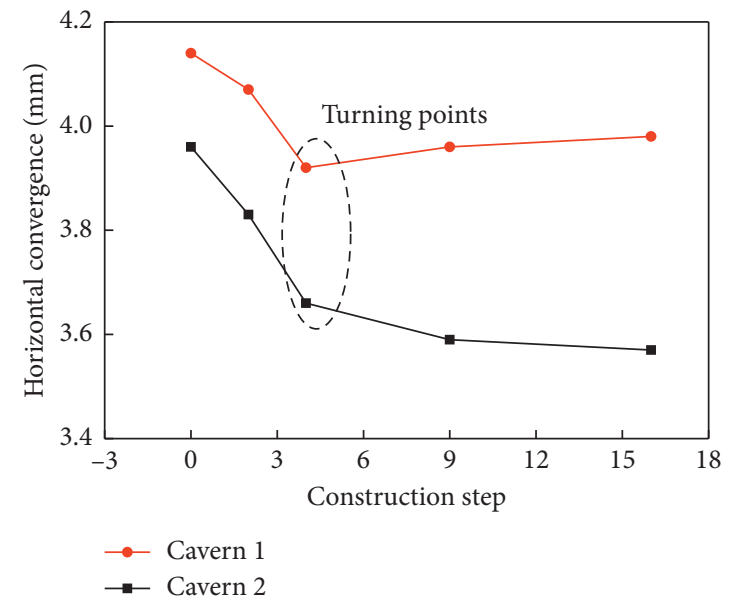

(c)

Figure 5: Horizontal deformation characteristics of caverns (1) and (2). (a) Horizontal convergence curve of cavern (1). (b) Horizontal convergence curve of cavern (2). (c) Change trend of convergence value of horizontal deformation curves of caverns (1) and (2). 


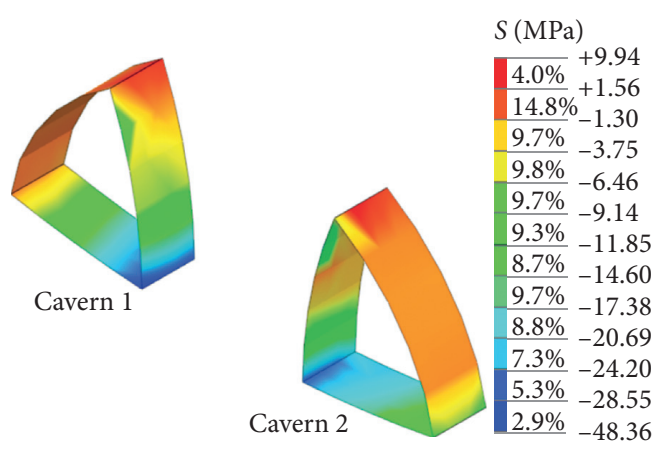

(a)

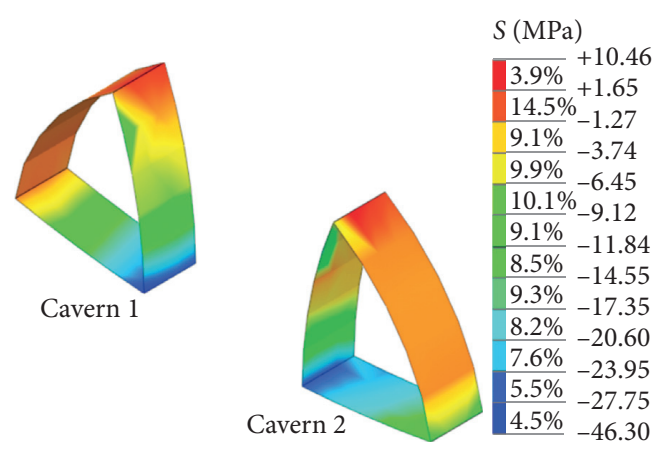

(c)

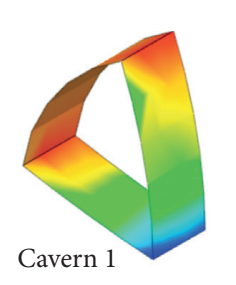

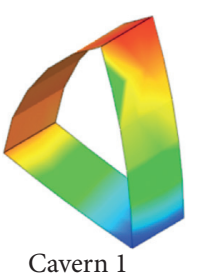

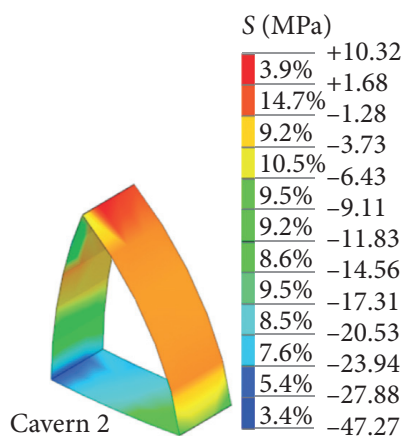

(b)
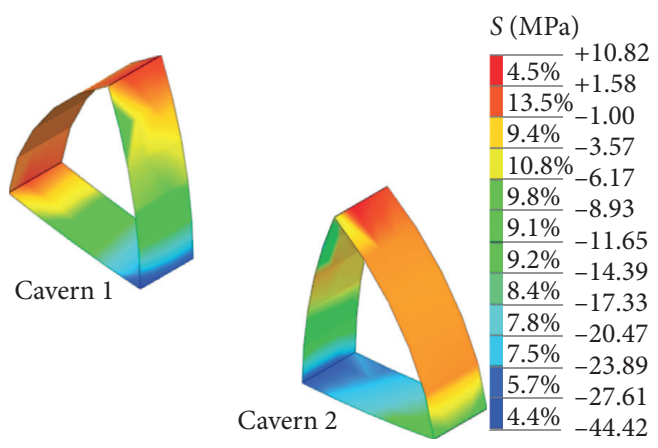

(d)

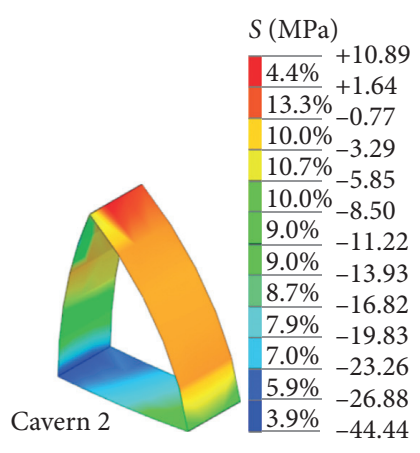

(e)

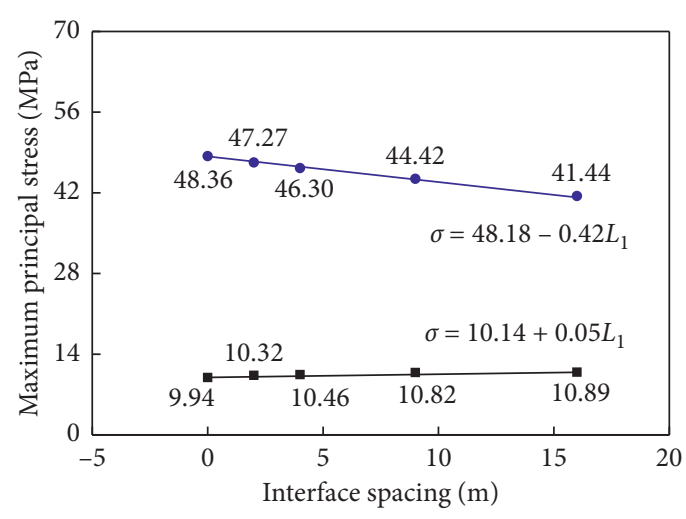

- Maximum tension stress

- Maximum compressive stress

(f)

FIgURe 6: Distribution characteristics of principal stress of supporting structure. (a) $L_{1}=0 \mathrm{~m}$. (b) $L_{1}=2 \mathrm{~m}$. (c) $L_{1}=4 \mathrm{~m}$. (d) $L_{1}=9 \mathrm{~m}$. (e) $L_{1}=16 \mathrm{~m}$. (f) Relationship between maximum principal stress and excavation face distance $\left(L_{1}\right)$.

stress distribution of supporting structure of caverns (1) and (2). The positive and negative values of principal stress represent tensile stress and compressive stress of the supporting structure, respectively. It can be seen from Figures 6(a)-6(e) that the maximum principal stress of the connection between the initial supporting and middle partition is mainly tensile stress. The load-bearing strength and surface settlement monitoring in this area should be strengthened to control the deformation and convergence during tunnel construction, thus improving the load strength of the tunnel and ability to resist the deformation of surrounding rock $[4,38]$. The middle and lower parts of the supporting structure are mainly subjected to compressive stress, and the connecting part of the middle partition and the central partition wall have the largest compressive stress.

Figure 6(f) shows the maximum principal stress of the supporting structure under different excavation face distances $L_{1}$. It can be seen from Figure 6(f) that with increasing excavation face distance $\left(L_{1}\right)$, the maximum tensile stress, and maximum compressive stress of the supporting structure have an opposite development trend. The maximum compressive stress is significantly greater than maximum tensile stress, and the maximum tensile stress is $20.55 \%$ $26.28 \%$ of maximum compressive stress. The maximum tensile stress increases from 9.94 to $10.89 \mathrm{MPa}$ with an increase of $9.56 \%$ when the excavation face distance increases 
from 0 to $16 \mathrm{~m}$, while the maximum compressive stress decreases from 48.36 to $41.44 \mathrm{MPa}$, decreasing by $14.31 \%$. It can be concluded that the increased excavation face distance $L_{1}$ has a significantly greater impact on the maximum compressive stress than maximum tensile stress. Fitting analysis found that the maximum tensile stress and maximum compressive stress both change linearly with increasing excavation face distance $\left(L_{1}\right)$.

From the analysis of stress distribution characteristics of supporting structure, it should first consider reducing the maximum tensile stress of supporting structure but also need to ensure that the maximum compressive stress of supporting structure should not be too large, then ensuring the stability and safety of the supporting structure during tunnel construction. From the maximum principal stress distribution in Figure 6(f), the average values of maximum tensile stress and maximum compressive stress of supporting structure are 10.49 and $45.56 \mathrm{MPa}$, respectively, which are very close to the maximum principal stress (10.46 and $46.30 \mathrm{MPa}$ ) of supporting structure when the excavation face distance $\left(L_{1}\right)$ is $4 \mathrm{~m}$. Therefore, it can be concluded that it is more reasonable when the excavation face distance is $4 \mathrm{~m}(1 D)$, which can ensure the stability of surrounding rock and shorten the construction period, which is consistent with the previous analysis results.

\subsection{Influence of Excavation Face Distance $L_{2}$ on Tunnel Stability}

3.2.1. Surface Settlement Characteristics. Figure 7 (a) shows the surface settlement curve of CK9 +462 section when the excavation face distance $L_{2}$ of caverns (2) and (3) takes different values. It can be seen from Figure $7(\mathrm{a})$ that the construction sequence of the large-section tunnel results in a greater surface settlement on the right side of the tunnel centerline than that on the left side and the most obvious surface settlement within the range of $-20 \sim 40 \mathrm{~m}$ from the tunnel centerline, with a settlement value of $5 \sim 19.25 \mathrm{~mm}$. The surface settlement around the tunnel is small, and the settlement value is $0 \sim 5 \mathrm{~mm}$. The surface settlement curves of caverns (2) and (3) under the different excavation face distances $\left(L_{2}\right)$ have a similar development trend, and all present a V-shaped distribution. A conclusion can be drawn from the above analysis that surface settlement trough is formed near the tunnel centerline under the influence of excavation, which is similar to the distribution characteristics of surface settlement curves in Figure 3.

Figure 7(b) shows the relationship between maximum vault settlement, maximum surface settlement at the tunnel centerline, and excavation face distance $\left(L_{2}\right)$. It can be seen from Figure 7(b) that when the excavation face distance $\left(L_{2}\right)$ is $0 \mathrm{~m}$, the surface settlement at the centerline and the vault settlement are the largest, which are 16.69 and $19.25 \mathrm{~mm}$, respectively. With increasing excavation face distance $\left(L_{2}\right)$, the surface settlement at the centerline and the vault settlement are in a decreasing trend. The surface settlements at centerline are reduced by $0.78 \%, 3.62 \%, 0.06 \%$, and $3.76 \%$, respectively. The vault settlements are reduced by $0.67 \%$,
$3.45 \%, 2.00 \%$, and $1.38 \%$, respectively. From this, we can see that the surface settlement at the tunnel centerline and the vault settlement decrease the most when the excavation face distance $\left(L_{2}\right)$ is $9 \mathrm{~m}$; however, there is no significant decrease in the surface settlement at the tunnel centerline and the vault settlement when the excavation face distance $\left(L_{2}\right)$ is greater than $9 \mathrm{~m}$ or less than $9 \mathrm{~m}$. It is concluded that the simultaneous excavation of the caverns (2) and (3) with an excavation face distance of $9 \mathrm{~m}$ can effectively reduce the surface settlement and improve the efficiency of safe excavation.

Moreover, comparing the maximum vault settlement and maximum surface settlement in Figure 7 (b) with Figure 3(b), it is found that surface settlement at tunnel centerline and the maximum vault settlement are 12.71 13.04 and 13.97 14.36 $\mathrm{mm}$ when the excavation face distance between caverns (1) and (2) is $L_{1}$. The surface settlement at the tunnel centerline and the maximum vault settlement are 15.36 16.69 and 17.84 19.25 $\mathrm{mm}$, which are $1.21 \sim 1.28$ times and 1.28 1.34 times the former, respectively. It can be seen that, compared with the influence of excavation of caverns (1) and (2), the excavation of caverns (2) and (3) has a significant impact on the surface settlement, and the impact on maximum vault settlement is significantly greater than that at tunnel centerline.

\subsubsection{Horizontal Deformation Characteristics of Caverns (1)} and (3). Taking the horizontal deformation and convergence characteristics of caverns (1) and (3) of CK9 + 462 section as the analysis object, the vault settlement and horizontal deformation curves of caverns (1) and (3) are obtained, as shown in Figure 8.

It can be seen from Figure 8(a) that in the early excavation stage of cavern (1), its vault shows a rapid settlement trend with different excavation face distances, and the maximum settlement of vault is close to $20 \mathrm{~mm}$. With increasing excavation step, the vault settlement degree of cave (2) is significantly reduced. It can be concluded that, with increasing excavation steps, the vault settlement curve of cavern (2) roughly experience first a rapid settlement and then a slow settlement. The boundary point of the settlement stage is $20 \mathrm{~mm}$, and the excavation step nodes are 22 31 steps. Besides, compared with the vault settlement curve of cavern (1) in Figure 4(a), it can be found that excavation face distance $\left(L_{2}\right)$ between caverns (1) and (3) significantly aggravated the tunnel's vault settlement, and the stable settlement stage of cavern (1) is relatively lagging behind when the excavation face distance is $L_{2}$.

It can be seen from Figure 8(b) that the horizontal deformation curve of cavern (1) obviously undergoes two stages of rapid deformation and then a convergence stage, which is basically consistent with the change trend of the vault settlement curve in Figure 8(a). Since the supporting structure in the initial excavation stage has not been fully constructed, the horizontal deformation of cavern (1) is relatively obvious. When the excavation step is greater than the $12^{\text {th }}$ step, horizontal deformation of cavern (1) is gradually slowed down, and convergence values of 


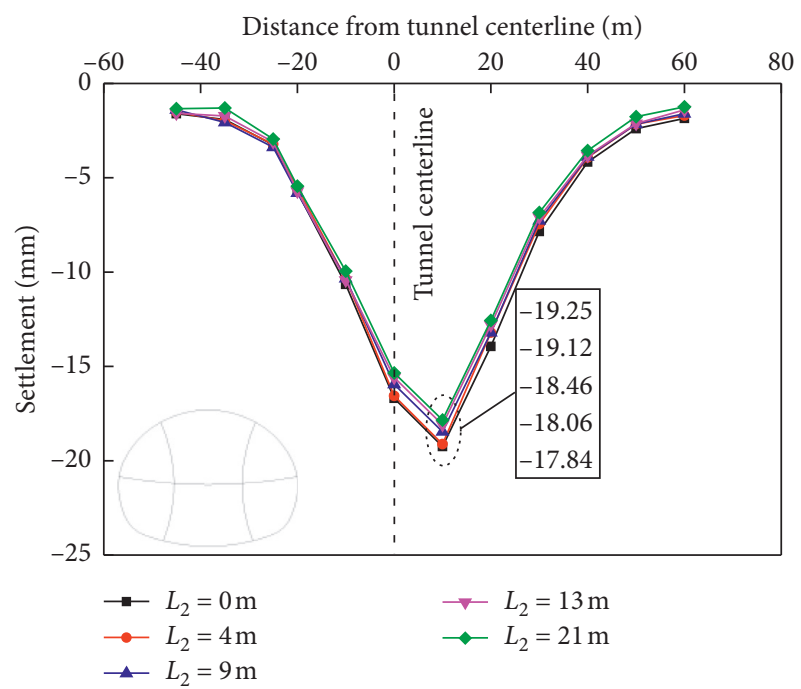

(a)

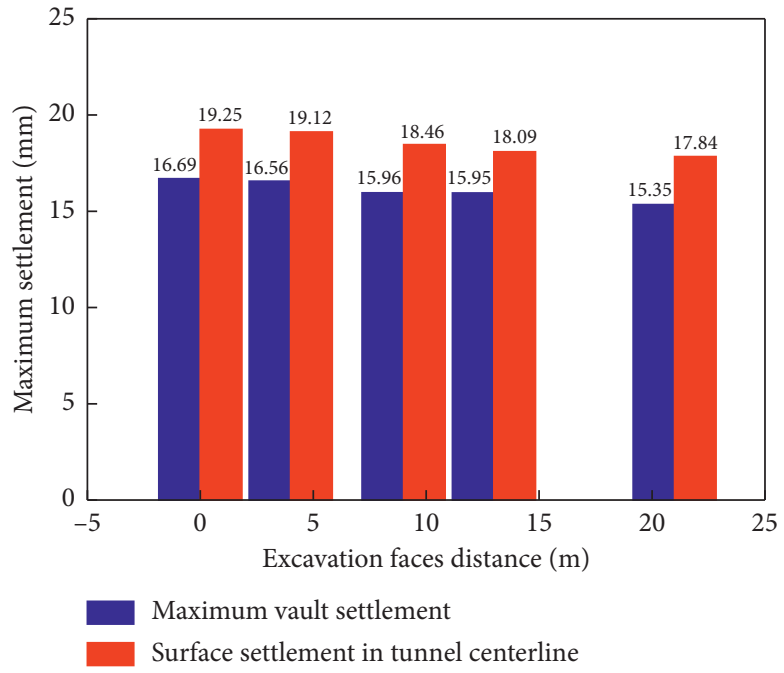

(b)

FiguRE 7: Surface settlement characteristics of CK9 + 462 section. (a) Surface subsidence curves with different excavation face distances. (b) Relationship between maximum vault settlement, surface settlement in tunnel centerline, and excavation face distance $\left(L_{2}\right)$.

horizontal deformation are 5.16, 5.25, 5.35, 5.41, and $5.45 \mathrm{~mm}$, respectively. It can be known that, with increasing excavation face distance $\left(L_{2}\right)$ of caverns (1) and (3), the deformation convergence value of cavern (1) gradually shows a gradually increasing trend. Therefore, horizontal deformation of cavern (1) can be effectively controlled when the excavation face distance between caverns (1) and (3) should not be too large.

Compared with the horizontal deformation curve of cave (1), the initial horizontal deformation dispersion degree of cave (3) is more obvious. The smaller the excavation face distance $\left(L_{2}\right)$ of caverns (1) and (3), the more obvious the initial horizontal deformation of cavern (3), but the earlier the horizontal deformation curve enters the convergence stage, as shown in Figure 8(c). Comparing the convergence values of horizontal deformation of caverns (1) and (3), it can be seen that the horizontal convergence value of cavern (3) is $4.08 \sim 4.52 \mathrm{~mm}$, and it gradually decreases as the excavation face distance $\left(L_{2}\right)$ increases. When the excavation face distance $\left(L_{2}\right)$ increases from 0 to $9 \mathrm{~m}$, the horizontal convergence value of cavern (3) decreases from 4.52 to $4.11 \mathrm{~mm}$, with a decrease of $9.07 \%$; when the excavation face distance $\left(L_{2}\right)$ increases from 9 to $21 \mathrm{~m}$, horizontal convergence value of cavern (3) is reduced from 4.11 to $4.08 \mathrm{~mm}$, with a decrease of $0.73 \%$. The above analysis shows that when the excavation face distance $\left(L_{2}\right)$ is greater than $9 \mathrm{~m}$, horizontal deformation cannot be effectively controlled by increasing the excavation face distance $\left(L_{2}\right)$. Therefore, when the excavation face distance $\left(L_{2}\right)$ of caverns (1) and (3) is $9 \mathrm{~m}(3 D)$, the tunnel settlement and horizontal deformation can be effectively restrained.

3.2.3. Principal Stress Characteristics of Supporting Structure of Caverns (1) and (3). Figure 9 shows the distribution characteristics of maximum principal stress in the supporting structure of caverns (1) and (3). It can be seen from Figure 9 that the maximum principal stress on the connecting part of the initial supporting and middle partition and the partition wall is tensile stress, and the other parts are mainly compressive stress. Compared with the principal stress of cavern (1), the excavation effect of cavern (3) reduces the maximum principal stress of supporting structure of cavern (1); maximum tensile stress and maximum compressive stress are reduced by $40 \% \sim 60 \%$ and $10 \% \sim 40 \%$, respectively.

Based on the stress distribution of maximum principal in Figure 9, Figure 10 shows the relationship of maximum tensile stress, maximum compressive stress of supporting structure, and excavation face distance $\left(L_{2}\right)$ of caverns (1) and (3), respectively. It can be seen from Figure 10 that with increasing excavation face distance $\left(L_{2}\right)$, the maximum tensile stress and maximum compressive stress both show a decreasing trend, and the maximum tensile stress is $10.51 \%$ $12.88 \%$ of maximum compressive stress. When the excavation face distance $\left(L_{2}\right)$ is increased from 0 to $21 \mathrm{~m}$, the maximum tensile stress is reduced from 4.40 to $3.43 \mathrm{MPa}$ with a reduction of $22.05 \%$. The maximum compressive stress is reduced from 41.88 to $26.63 \mathrm{MPa}$ with a decrease of $36.41 \%$. It can be concluded that maximum compressive stress can be effectively reduced by appropriately increasing the excavation face distance $\left(L_{2}\right)$, and it will have no obvious effect on the maximum tensile stress.

In addition, the relationships between maximum compressive stress of caverns (1) and (3) and excavation face distance $\left(L_{2}\right)$ show that the maximum compressive stress with excavation face distance $\left(L_{2}\right)$ of $4,9,13$, and $21 \mathrm{~m}$ is reduced by $3.65 \%, 15.82 \%, 26.46 \%$, and $36.41 \%$, comparing with the maximum compressive stress when the excavation face distance $\left(L_{2}\right)$ is $0 \mathrm{~m}$. It can be concluded that maximum compressive stress is reduced significantly when the excavation face distance $\left(L_{2}\right)$ is greater than $9 \mathrm{~m}$. Therefore, it is recommended that excavation face distance $\left(L_{2}\right)$ of caverns 


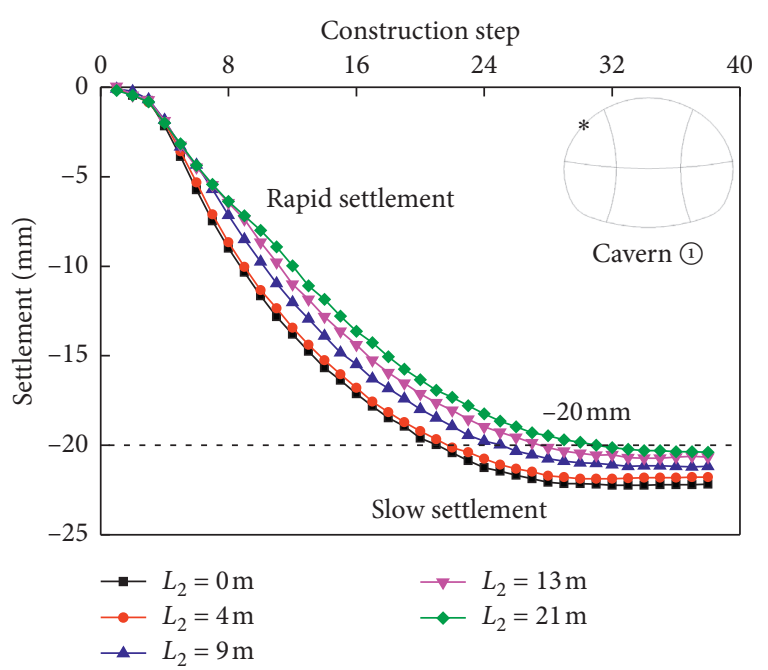

(a)

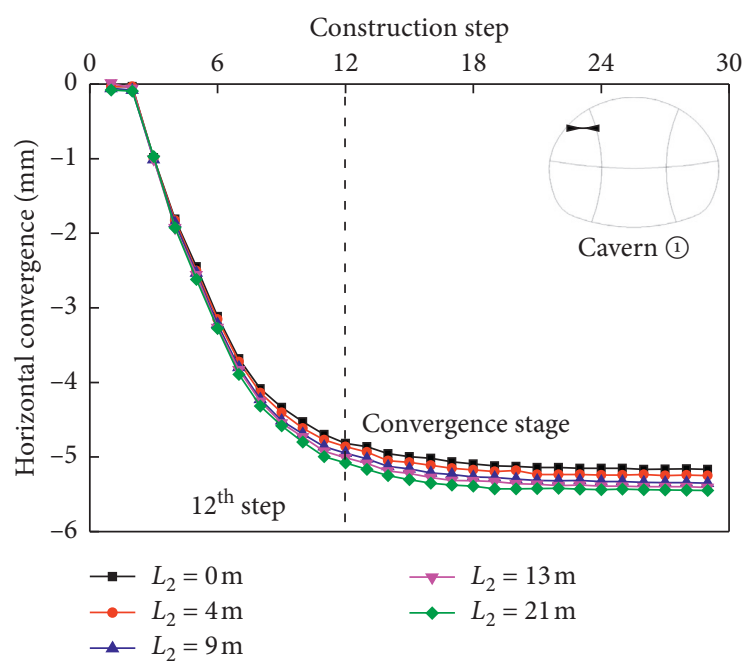

(b)

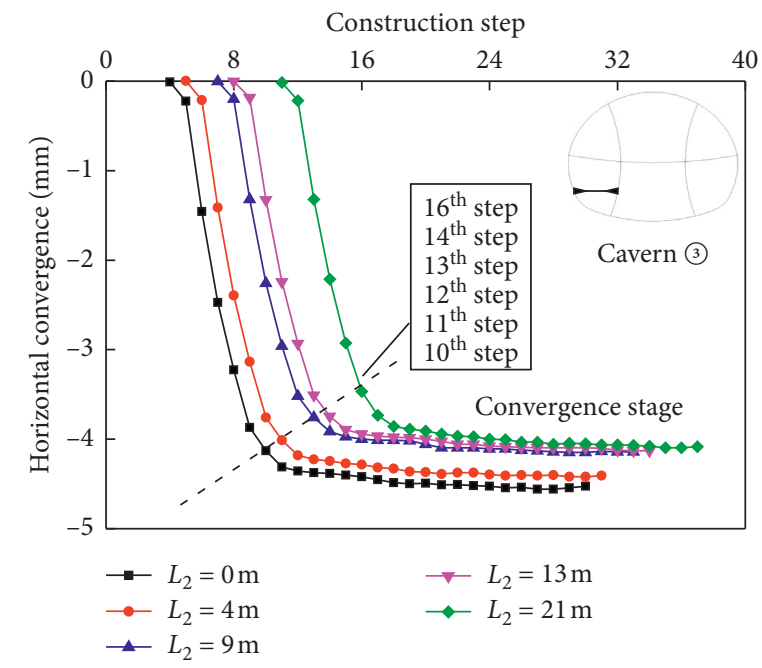

(c)

FIGURE 8: Horizontal deformation and convergence characteristics of the CK9 + 462 section. (a) Vault settlement curve of cavern (1). (b) Horizontal convergence curve of cavern (1). (c) Horizontal convergence curve of cavern (3).

(1) and (3) is $9 \mathrm{~m}$, so as to ensure the stability of surrounding rock and effectively shorten the construction period.

\subsection{Influence of Excavation Face Distance $L_{3}$ on Tunnel Stability}

3.3.1. Surface Settlement Characteristics. Figure 11 shows surface settlement curves of CK9 + 462 section after the excavation of caverns (5) and (6) is completed. It can be seen that the excavation of caverns (5) and (6) has a lower discrete degree of vault settlement, and its change trend is similar to the vault settlement curve caused by the excavation of caverns (1), (2), and (3). However, the surface subsidence in Figure 11 is significantly smaller than that in Figure 7 and is significantly larger than that in Figure 3. It can be inferred from the above that the impact of excavation face distance $\left(L_{3}\right)$ on the surface settlement is greater than the excavation face distance $\left(L_{1}\right)$ but less than the excavation face distance $\left(L_{2}\right)$.
It can also be seen from Figure 11 that the CK9 +462 section has a significant surface settlement within the range of $-20 \sim 40 \mathrm{~m}$ from the tunnel centerline; the surface settlement is $2.5 \sim 18.13 \mathrm{~mm}$, forming a significant V-shaped settlement trough. However, the surface area far away from the tunnel centerline has insignificant settlement deformation, and its settlement is only $0 \sim 2.50 \mathrm{~mm}$. Cording [29] showed that after the completion of tunnel excavation, the asymmetric settlement trough formed on the tunnel surface was related to the excavation of the preceding tunnel.

Simultaneously, the maximum vault settlement occurs at a position $10 \mathrm{~m}$ away from the tunnel centerline. The maximum vault settlement at different excavation face distances $\left(L_{3}\right)$ is $17.77 \sim 18.13 \mathrm{~mm}$, and its settlement value is about 1.15 times the settlement value $(15.47 \sim 15.68 \mathrm{~mm})$ at the tunnel centerline. However, the surface settlement at the tunnel centerline gradually increases as excavation face distance $\left(L_{3}\right)$ increases, which is significantly different from the change trend of settlement curves at the centerline when excavating with 


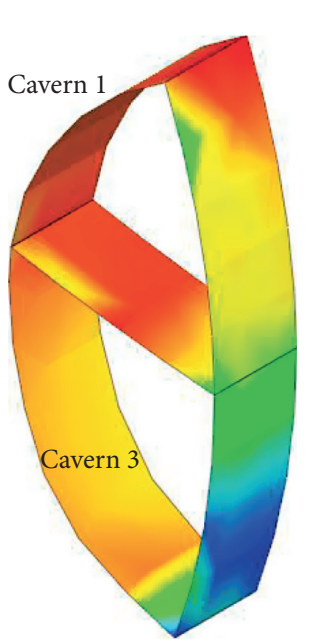

(a)

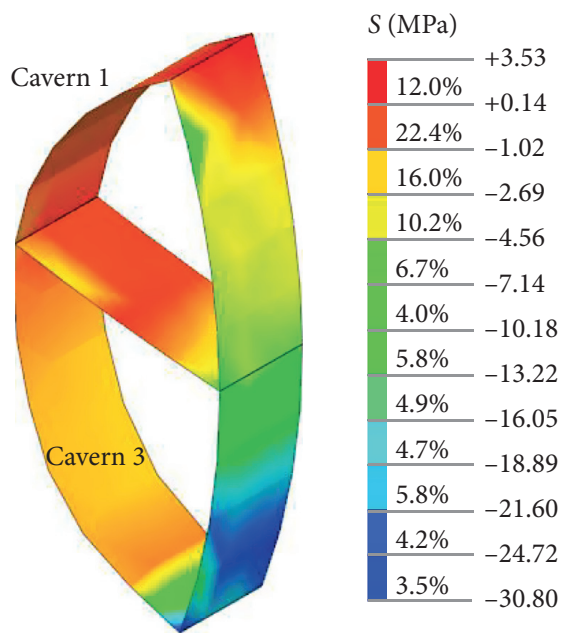

(d)

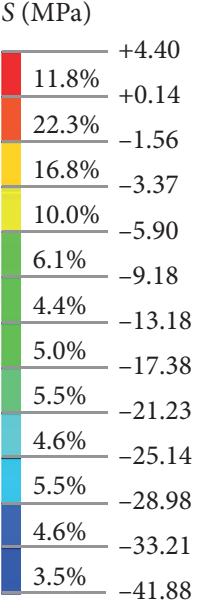

(b)
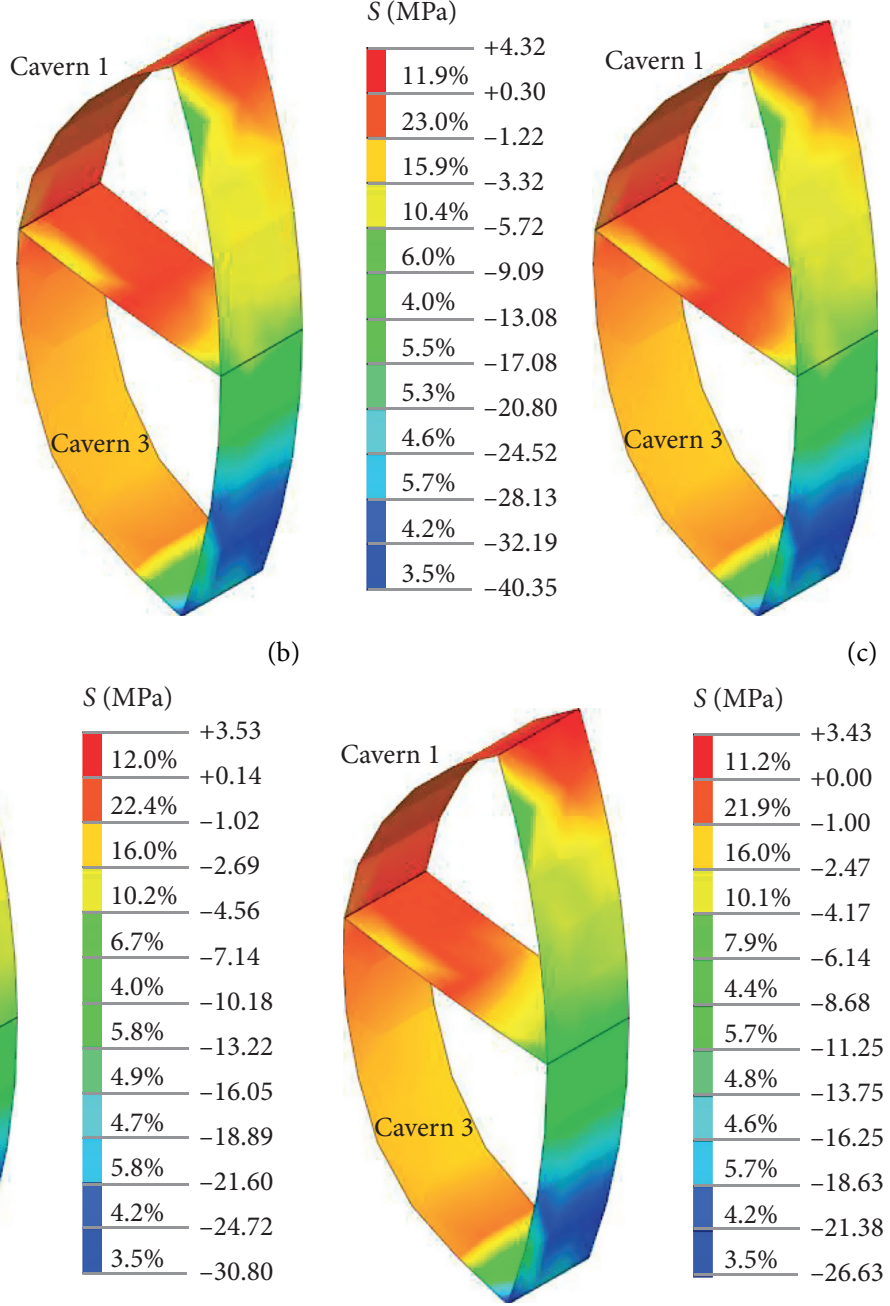

(e)
$S(\mathrm{MPa})$
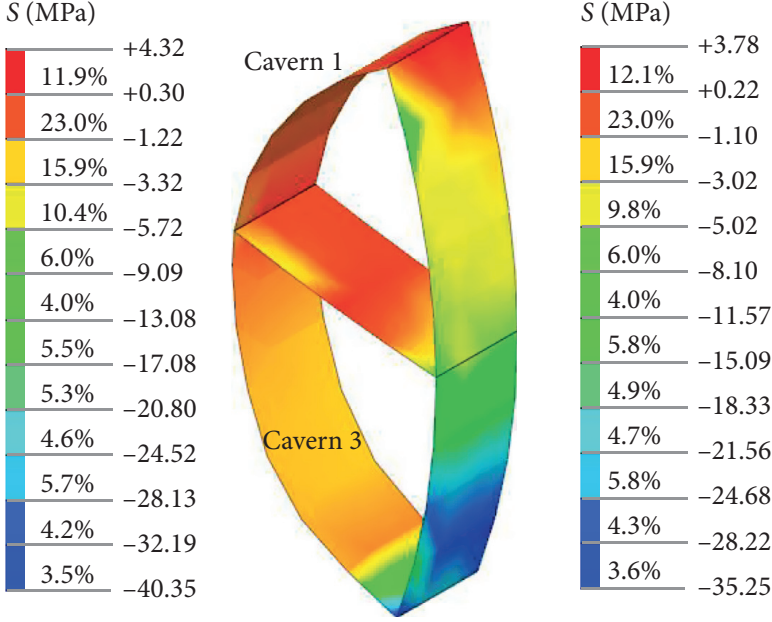

(c)

FIGURE 9: Distribution characteristics of maximum principal stress of caverns (1) and (3). (a) $L_{2}=2 \mathrm{~m}$, (b) $L_{2}=4 \mathrm{~m}$, (c) $L_{2}=9 \mathrm{~m}$, (d) $L_{2}=13 \mathrm{~m}$, and (e) $L_{2}=21 \mathrm{~m}$.

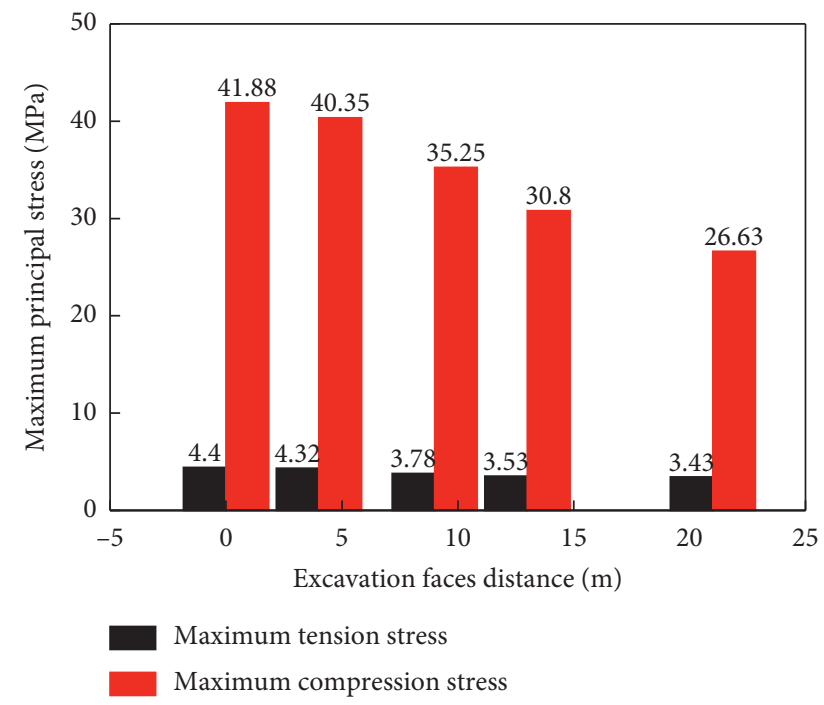

FIGURE 10: Maximum principal stress of supporting structure of caverns (1) and (3).

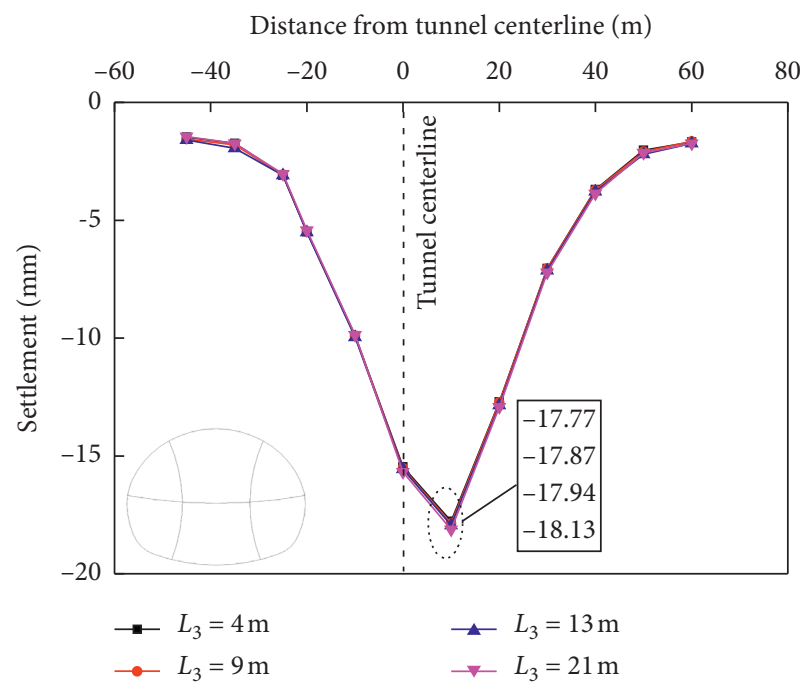

Figure 11: Surface subsidence curves of the CK9+462 section. 
excavation face distances $L_{1}$ and $L_{2}$. From the above analysis, it can be concluded that appropriately reducing the excavation face distance $\left(L_{3}\right)$ can better control the surface settlement.

3.3.2. Vault Settlement Characteristics of Caverns (1), (2), and (5). Under the excavation influence of caverns (5) and (6), the vault settlement characteristic of caverns (1), (2), and (5) is taken as the research object. Figure 12 shows the vault settlement curves and the relationship between maximum vault settlement and excavation face distance $\left(L_{3}\right)$. It can be seen from Figures 12(a)-12(c) that the development trends of vault settlement curves are similar, including two stages of a rapid settlement and a slow settlement. The boundary values of the settlement stages are $20,20,21 \mathrm{~mm}$, respectively.

Since caverns (1) and (2) are at the symmetrical excavation position, settlement curves of the two vaults have the same change characteristics with a low dispersion degree, and its convergence value is approximately equal when the settlement curve tends to the equilibrium state. However, due to the influence of the excavation of caverns (1) and (2), vault settlement values of cavern (5) with different excavation face distances $\left(L_{3}\right)$ are relatively large, especially in the early excavation stage. The settlement data at the later excavation stage of cave (5) shows that the greater the excavation face distance $\left(L_{3}\right)$, the greater the vault settlement value at the stable settlement stage.

Moreover, Figure 12(d) shows the relationship between the maximum vault settlement of caverns (1), (2), and (5) and excavation face distance $\left(L_{3}\right)$. It can be seen that the maximum vault settlements of caverns (1), (2), and (5) all increase with increasing excavation face distance $\left(L_{3}\right)$, and the maximum vault settlement of caverns (1) and (2) is significantly smaller than that of cavern (5). From the above analysis, it can be concluded that, during the construction process, the smaller excavation face distance $\left(L_{3}\right)$ can effectively reduce the vault settlement of caverns (1), (2), and (5).

\subsubsection{Horizontal Deformation Characteristics of Caverns (1)} and (3). Figure 13 shows horizontal deformation curves of caverns (1) and (3) and the convergence characteristics. It can be seen that, with the excavation of caverns (5) and (6), the horizontal deformation curves of caverns (1) and (3) have generally experienced a rapid deformation stage and a gradual convergence stage. And the horizontal convergence value of cavern (1) is $3.50 \sim 4.50 \mathrm{~mm}$, which is significantly smaller than the horizontal convergence value of cave (3).

However, the horizontal deformation values of caverns (1) and (3) in Figure 13 show a significant abrupt change, closely related to excavation and supporting. Combined with the construction process of the double-side heading method, it is believed that caverns (1) and (3) have completed the soil excavation before excavation of caverns (5) and (6), and the initial supporting and temporary steel supporting have supporting and restraint functions. During the excavation of cavern (5), the gradually closed supporting structure has a lateral constraint on the horizontal deformation of cavern (3), leading to a sudden decrease in the horizontal deformation of cavern (3) at the construction steps $9^{\text {th }}, 11^{\text {th }}, 12^{\text {th }}$, and $14^{\text {th }}$. With the gradual excavation of cavern (6), the steel supporting between caverns (3) and (6) is removed, resulting in the removal of lateral restraint of cavern (3), thus causing its horizontal deformation to increase suddenly.

Comparing Figures 13(a) and 13(b), we can find that the convergence values of horizontal deformation of caverns (1) and (3) are $4.19 \sim 4.75 \mathrm{~mm}$ and $5.11 \sim 5.18 \mathrm{~mm}$, respectively. The horizontal deformation of cavern (3) is significantly greater than cavern (1), and deformation monitoring of cavern (3) should be strengthened during the construction process. Besides, with increasing excavation face distance $\left(L_{3}\right)$ of caverns (5) and (6), the convergence value of horizontal deformation of caverns (1) and (3) shows an increasing trend. It can be seen that, in order to reduce the tunnel horizontal deformation, the excavation face distance $\left(L_{3}\right)$ should be minimized, which is consistent with the analysis of the above results.

3.3.4. Principal Stress Characteristics of Supporting Structure of the CK9+462 Section. Figure 14 shows the principal stress characteristics of supporting structures of the CK9 + 462 section and the relationship between the maximum principal stress and excavation face distance $\left(L_{3}\right)$. The positive stress value and negative stress value indicate tensile stress and compressive stress of the supporting structure. It can be seen from Figures 14(a)-14(d) that the distribution characteristics of maximum principal stress of the supporting structure are similar to those of the supporting structure in Figures 6 and 9. The maximum principal stress at the connection between the initial supporting and partition wall is mainly tensile stress, where the monitoring of bearing strength and soil settlement should be strengthened to control the deformation characteristics of the supporting structure during construction. The partition wall between cavern (3), cavern (4), and cavern (6) is mainly composed of compressive stress, and compressive stress appears in some parts of the partition wall of caverns (1), (2), and (5).

The principal stress in Figures 14(a)-14(d) also shows that stress concentration occurs at the connections of steel supporting and initial supporting. The bottom of the supporting structure is mainly concentrated in compressive stress, and the maximum compressive stress is $38.43 \sim 38.80 \mathrm{MPa}$. The supporting structure of vault is mainly concentrated in tensile stress, and the maximum tensile stress is $4.44 \sim 4.76 \mathrm{MPa}$. Therefore, during the construction process, it is necessary to strengthen the deformation monitoring of connection between steel supporting and initial supporting $[33,34,36,38]$, thus improving the load strength of supporting structure and resistance ability of deformation of surrounding rock.

Figure 14(e) shows the relationship between the maximum principal stress of the supporting structure of the CK9 +462 section and the excavation face distance $\left(L_{3}\right)$. It can be seen from Figure 14(e) that the maximum tensile stress and maximum compressive stress of the supporting structure are $4.44 \sim 4.76 \mathrm{MPa}$ and $38.43 \sim 38.80 \mathrm{MPa}$, respectively. The maximum compressive stress is about $8.15 \sim 8.66$ times the maximum tensile stress, and the corresponding change rate of maximum compressive stress and maximum 


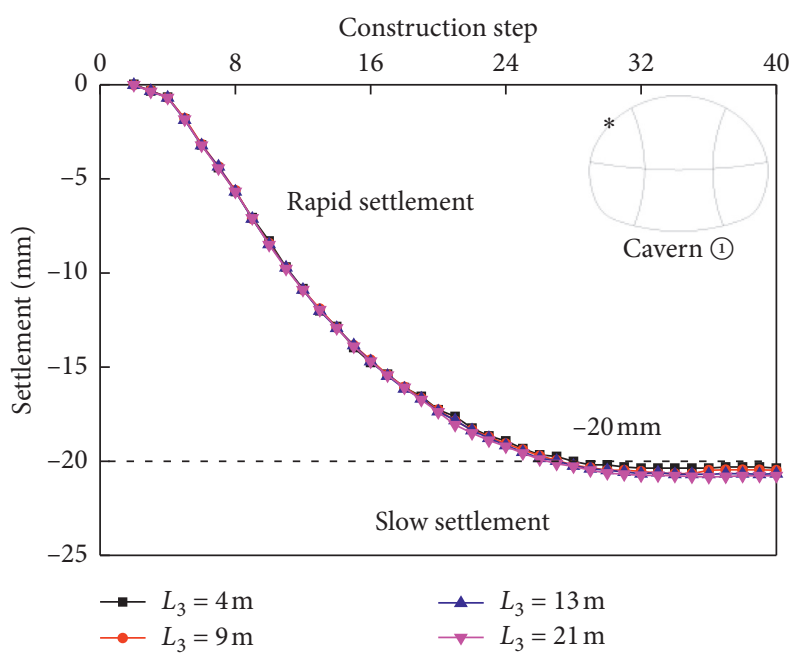

(a)

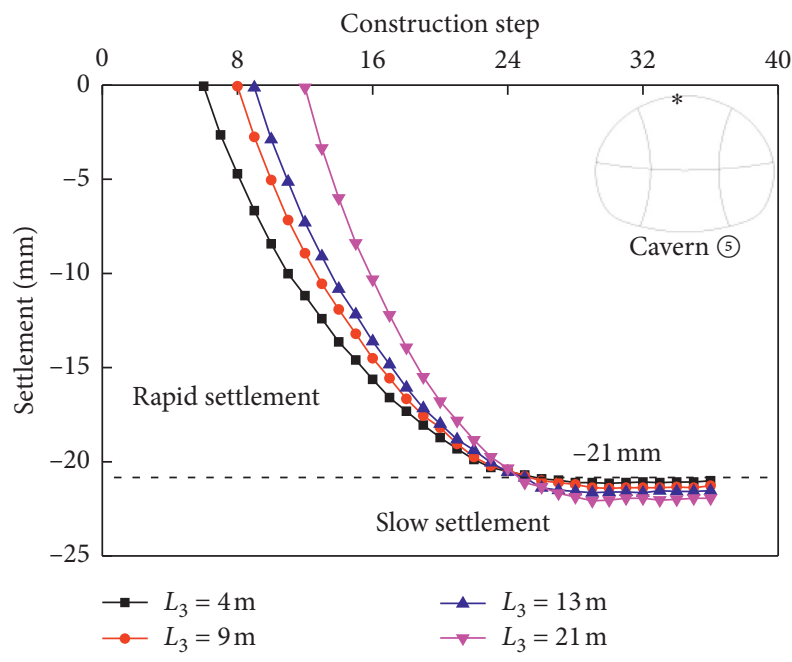

(c)

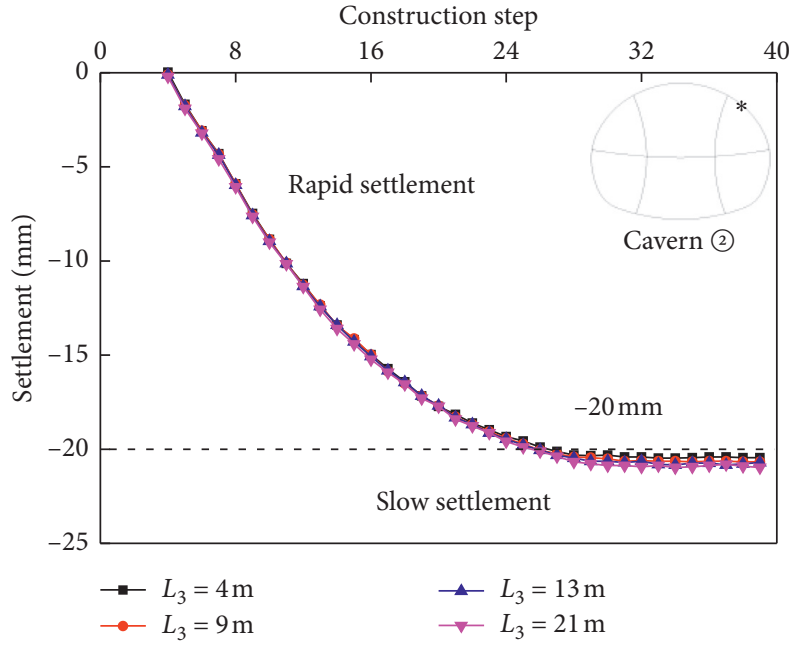

(b)

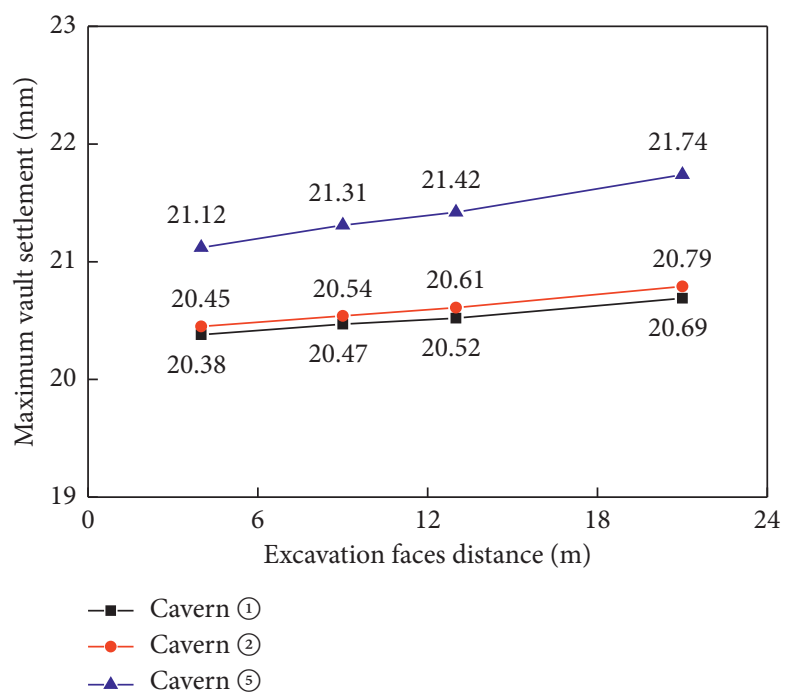

(d)

Figure 12: Vault settlement characteristics of caverns (1), (2), and (5). (a) Vault settlement curve of cavern (1). (b) Vault settlement curve of cavern (2). (c) Vault settlement curve of cavern (5). (d) Relationship between maximum vault settlement and excavation face distance $\left(L_{3}\right)$.

tensile stress both are $0.02 \mathrm{MPa} / \mathrm{m}$. It can be seen that since maximum tensile stress and maximum compressive stress both increase with increasing excavation face distance $\left(L_{3}\right)$, the excavation face distance $\left(L_{3}\right)$ should be minimized during the excavation process of caverns (5) and (6).

The section size of the tunnel between Yannan 4th Road Station and Datang Furongyuan Garden Station is $12.13 \mathrm{~m} \times 10.03 \mathrm{~m}$ as shown in Figure 1, and its excavation area is obviously larger than $100 \mathrm{~m}^{2}$. According to the International Tunnel Association's criteria for tunnel judgment [34], the tunnel in the excavation section is a largesection tunnel, and the excavation process should strictly follow the construction principle of "short excavation and strong support" [39], and the surface settlement, vault settlement, and horizontal deformation are the focus of construction monitoring. Synthesizing the above factors, it can be seen that, in order to reduce the surface settlement and horizontal deformation and to better exert the load capacity of supporting structure, the excavation face distance $\left(L_{3}\right)$ between caverns (5) and (6) is $9 \mathrm{~m}(3 D)$.

Based on the above analysis, it can be concluded that when the double-sides heading method is used for loess tunnel construction, the excavation face distance $\left(L_{1}\right)$ of caverns (1) (2) and caverns (3) (4) is $4 \mathrm{~m}$ (1D), excavation face distance $\left(L_{2}\right)$ of caverns (2) (3) is $9 \mathrm{~m}(3 D)$, and excavation face distance $\left(L_{3}\right)$ of caverns (4) (5) is $9 \mathrm{~m} \mathrm{(3D)}$, which can improve the stability of surrounding rock mass and shorten the construction period.

Based on the results of the numerical analysis, the construction suggestions for the shallow-buried and largesection loess tunnel are as follows: (1) when excavating the large-section loess tunnels with the double-sides heading method, the footage length of each cycle should be controlled at about $0.50 \mathrm{~m}$, and excavation face distance should 


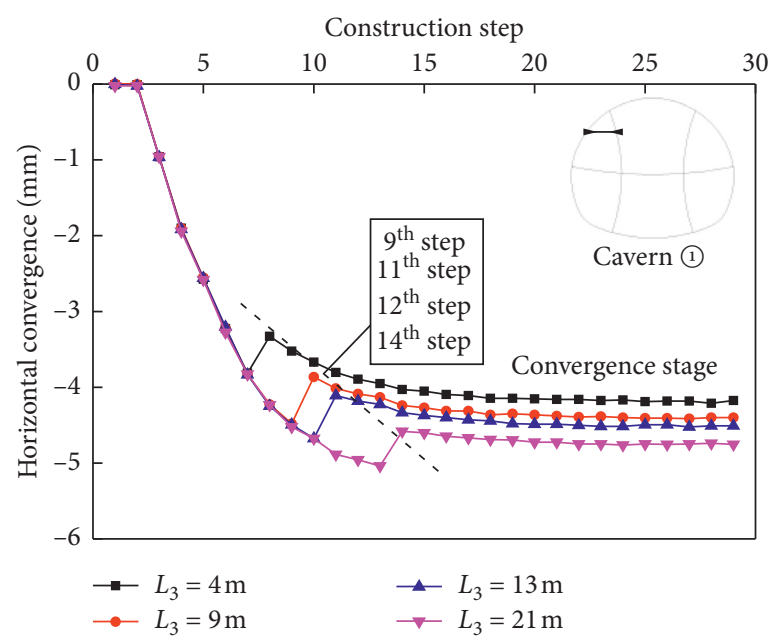

(a)

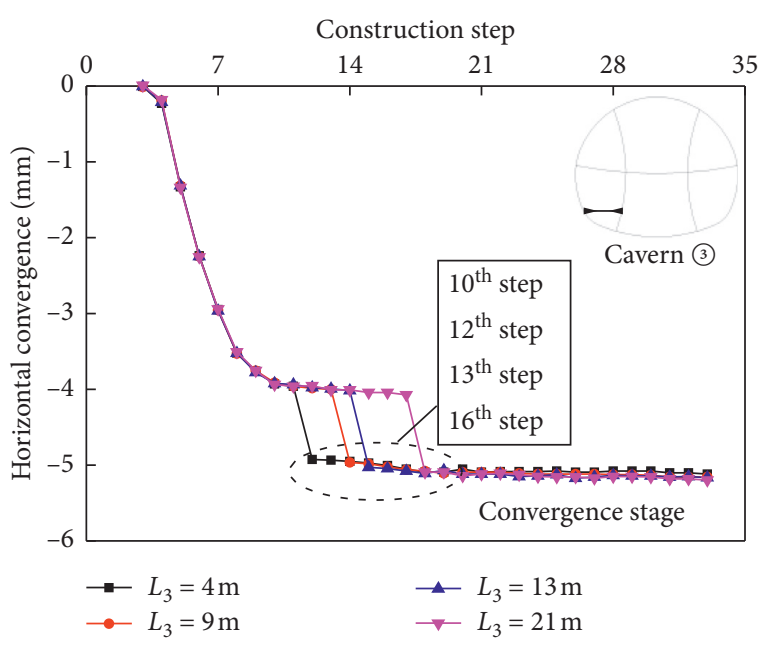

(b)

Figure 13: Horizontal deformation characteristics of caverns (1) and (3). (a) Horizontal convergence curve of cavern (1). (b) Horizontal convergence curve of cavern (3).

be reasonably controlled. (2) The loess tunnel is excavated by the method of up and down steps and the step length should be $3 \sim 5 \mathrm{~m}$ to ensure the stability of the excavation face. The initial supporting and temporary supporting should be implemented in time after excavation. (3) In the interval where the clear distance between the construction tunnel and the existing tunnel is less than $9 \mathrm{~m}$, it is necessary to apply tension bolts to reduce the deformation middle rock column.

\section{Engineering Measurement and Analysis}

4.1. Monitoring Point Layout and Monitoring Content. The tunnel from Yannan 4th Road Station to Datang Furongyuan Garden Station on Xi'an Metro Line 4 has the characteristics of large section, small tunnel clearance, crossing the loess layer, and weak surrounding rock. Therefore, the double-sides heading method is used for the excavation to reduce the construction risks $[17,18,24]$. The supporting structure parameters are shown in Table 1.

Based on the Code for Monitoring Measurement of Urban Rail Transit Engineering (GB50911-2013) [33] and the actual situation on the site, the monitoring level of the research section of this tunnel is determined to be Class II. Setting up the monitoring sections at $100 \mathrm{~m}$ intervals in the direction perpendicular to the tunnel axis, there are 11 monitoring points for each monitoring section. The layout of the monitoring points of surface settlement, vault settlement, and horizontal deformation is shown in Figure 15.

In this study, the surface settlement in the tunnel-affected area is taken as the main monitoring area, the distance between monitoring points is $3 \sim 5 \mathrm{~m}$, and the distance between monitoring points in the secondary influence area is $5 \sim 10 \mathrm{~m}$. During the tunnel excavation process, the construction site mainly monitors the surface settlement, vault settlement, and horizontal convergence characteristics of this research section.
The maximum allowable value of surface settlement, vault settlement, and horizontal deformation and corresponding maximum allowable rate are shown in Table 2. During the construction process, if the values of surface settlement, vault settlement, and horizontal deformation of monitoring points or its change rates exceed the maximum allowable value or the maximum allowable rate shown in Table 2, it means that the tunnel surrounding rock is unstable $[13,24]$. The excavation should be stopped immediately, the tunnel should be reinforced and protected, and the number of measuring points should be increased.

4.2. Analysis and Discussion of Monitoring Results. Combining with the monitoring data, the next section of the paper presents the surface settlement, vault settlement, horizontal deformation, and convergence data of tunnel construction using the double-sides heading method. Due to the excessive monitoring data, Section 4.2 only analyzes and discusses the monitoring data of characteristic the CK9 +415 section.

4.2.1. Surface Settlement Characteristics. Affected by tunnel excavation, the vertical settlement displacement generated on the ground surface is an important parameter to determine the stability of the surrounding rock mass. Taking the characteristic CK9 + 415 section as the monitoring and analysis object, Figure 16 shows the surface settlement curves from 9 November 2017 to 22 January 2018. In Figure 16, the horizontal coordinate represents the distance from the first monitoring point (i.e., the first measuring point on the left of Figure 15 is the 0 point coordinate in Figure 16), the negative value of the vertical coordinate represents surface settlement, and the positive value represents surface arch. The longitudinal black-dotted line is the tunnel centerline of Metro Line 4 (i.e., the longitudinal reddotted line in Figure 15). 


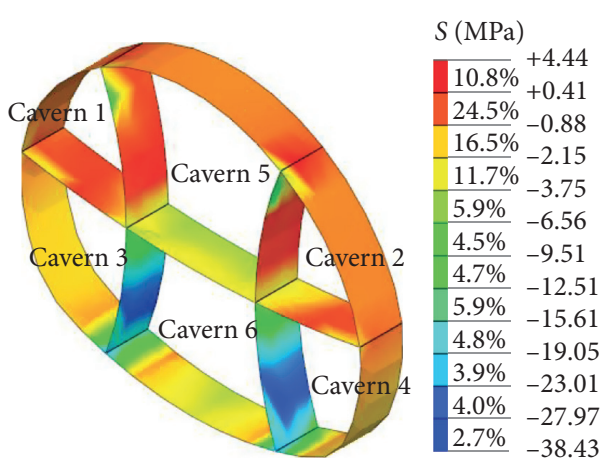

(a)

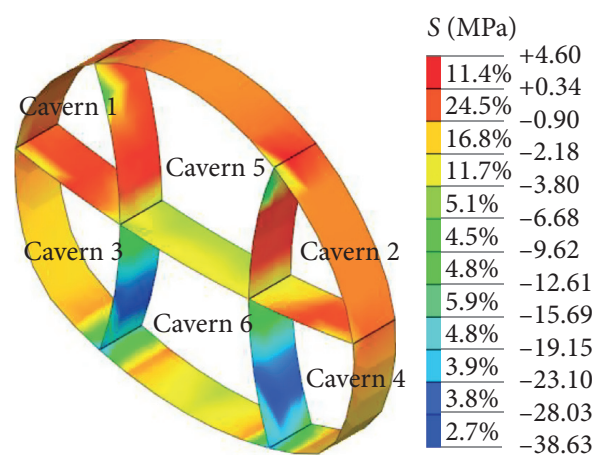

(c)

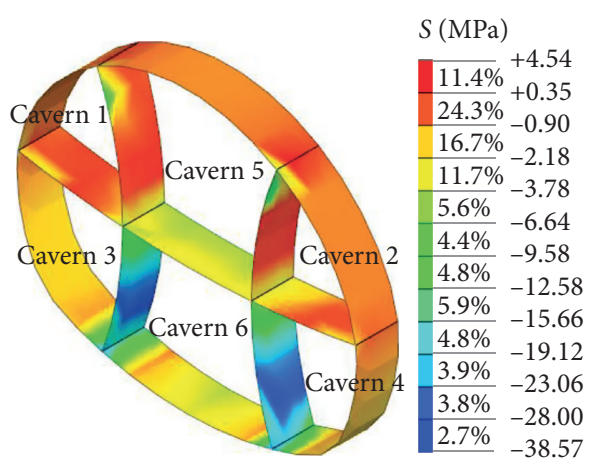

(b)

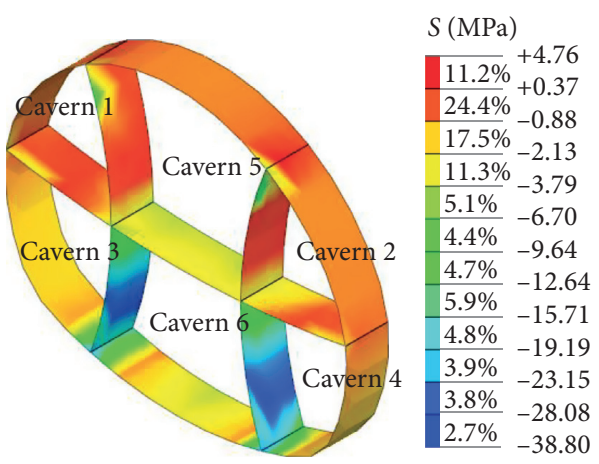

(d)

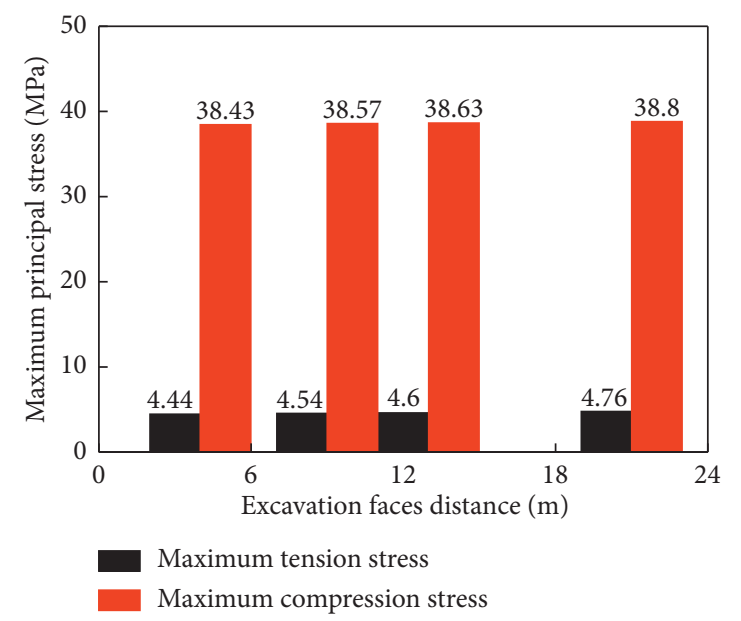

(e)

Figure 14: Principal stress characteristics of supporting structure of the CK9 +462 section. (a) $L_{3}=4 \mathrm{~m}$. (b) $L_{3}=9 \mathrm{~m}$. (c) $L_{3}=13 \mathrm{~m}$. (d) $L_{3}=21 \mathrm{~m}$. (e) Relationship between maximum principal stress and excavation face distance $\left(L_{3}\right)$.

The position of the monitoring point in Figure 16 corresponds to the monitoring point in Figure 15. Monitoring points 6 to 11 are used to monitor the surface settlement data, and monitoring points 1 to 5 are used to monitor the impact of excavation on the surface settlement of the existing tunnel. The surface settlement characteristics of the existing tunnel have been presented in another paper, and this study will not be repeated here. The following conclusions can be drawn by analyzing the surface settlement data.

The double-sides heading method has a significant impact on the surface settlement. It can be seen from
Figure 16 that the ground surface in the range of $-17 \sim 6 \mathrm{~m}$ from the tunnel centerline has a significant settlement trend (in the dashed frame). The closer the area to the tunnel centerline, the greater the ground surface settlement. The maximum surface settlement at the tunnel centerline $(x=25 \mathrm{~m})$ is about $0.82 \sim 19.61 \mathrm{~mm}$, and its maximum settlement value is about $65.37 \%$ of the maximum allowable value $(30 \mathrm{~mm})$ in Table 2 . Obviously, tunnel stability meets the safety construction requirements. However, the surface settlement within the range of $-25 \sim-17$ and $31 \sim 36 \mathrm{~m}$ from the tunnel centerline is not obvious, and the settlements are $0.30 \sim 7.74$ and $0.02 \sim 9.37 \mathrm{~mm}$, respectively. It can be seen 


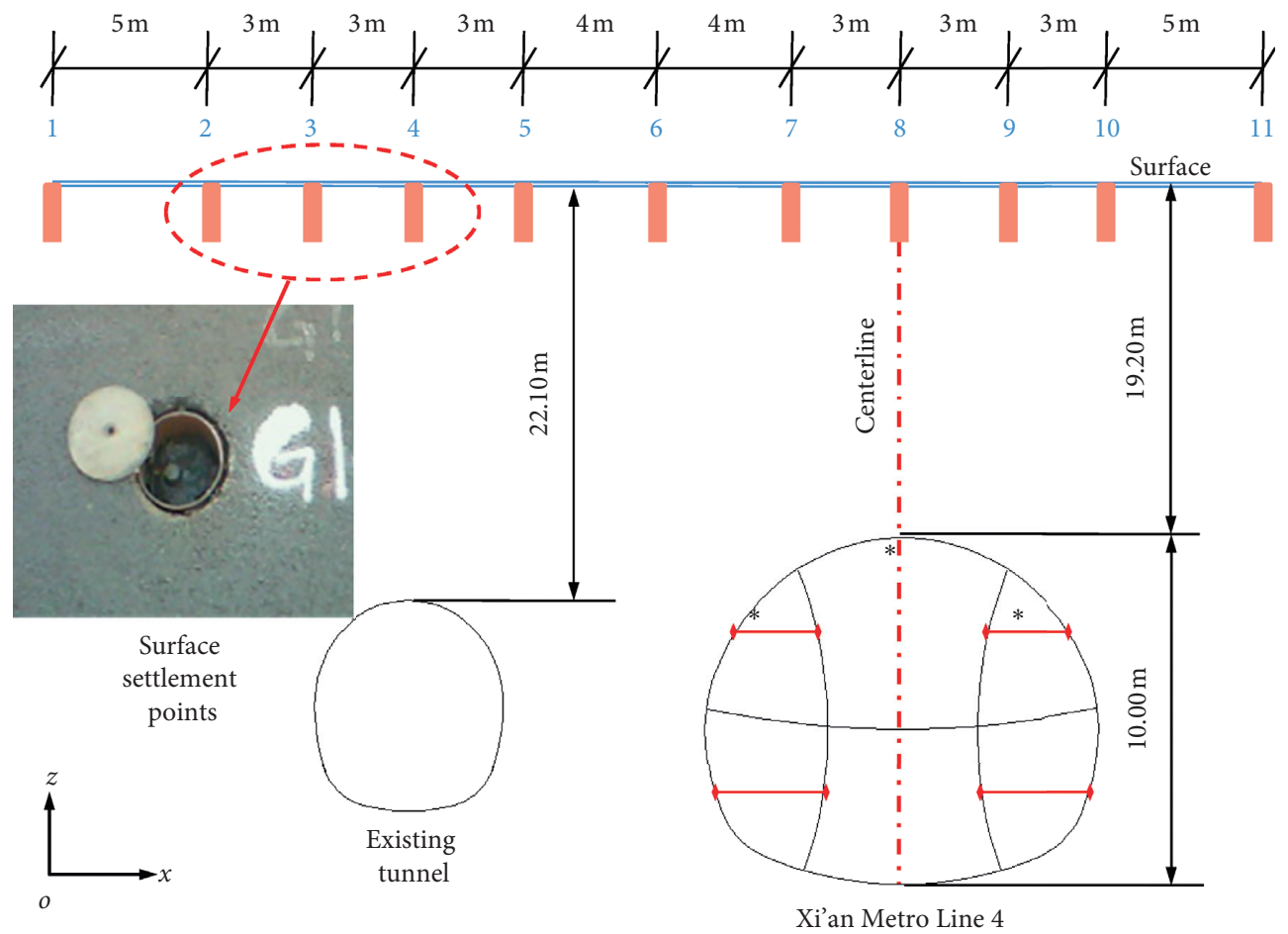

$*$ Vault settlement point.

— Horizontal convergence monitoring.

FIGURE 15: Layout of monitoring points.

TABle 2: Maximum allowable values [13, 24, 33].

\begin{tabular}{lcc}
\hline Contents & Maximum allowable value $(\mathrm{mm})$ & Maximum change rate $(\mathrm{mm} / \mathrm{d})$ \\
\hline Surface settlement & 30 & 4 \\
Vault settlement & 40 & 5 \\
Horizontal deformation & 20 & 2 \\
\hline
\end{tabular}

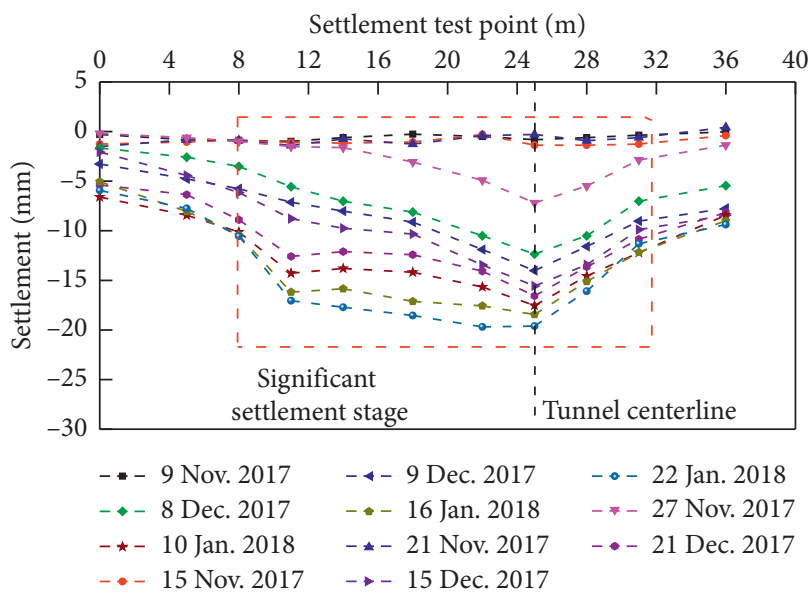

Figure 16: Surface settlement curves.

that the tunnel construction of the double-side heading method has a significant impact on the surface settlement within the range of $-11 \sim 31 \mathrm{~m}$ from the tunnel centerline, resulting in a $\mathrm{V}$-shaped settlement trough on the ground surface. It is worth noting that surface settlement troughs monitored by construction have a significant symmetry about the tunnel centerline, which is different from the numerical simulation results shown in Figures 3, 7, and 11. Therefore, the settlement monitoring of this sensitive settlement area should be strengthened during construction $[38,39]$.

The time-history curve of surface settlement and its maximum change rate are shown in Figure 17. It can be seen from Figure 17(a) that the excavation effect has a significant impact on the surface settlement at the tunnel centerline, and the time-history curve has experienced an insignificant settlement stage, a rapid settlement stage, and a slow settlement stage as the excavation time increases. Based on data analysis, it is found that from 9 November 2017 to 21 November 2017, the ground surface has insignificant subsidence with a subsidence value of $0 \sim 1.07 \mathrm{~mm}$, and the timehistory curve shows a horizontal trend. The maximum change rate of the ground settlement is $0.18 \mathrm{~mm} /$ day on 21 November 2017.

From 21 November 2017 to 9 December 2017, the surface settlement curve enters the rapid settlement stage with a maximum subsidence value of $14.64 \mathrm{~mm}$. Compared with 


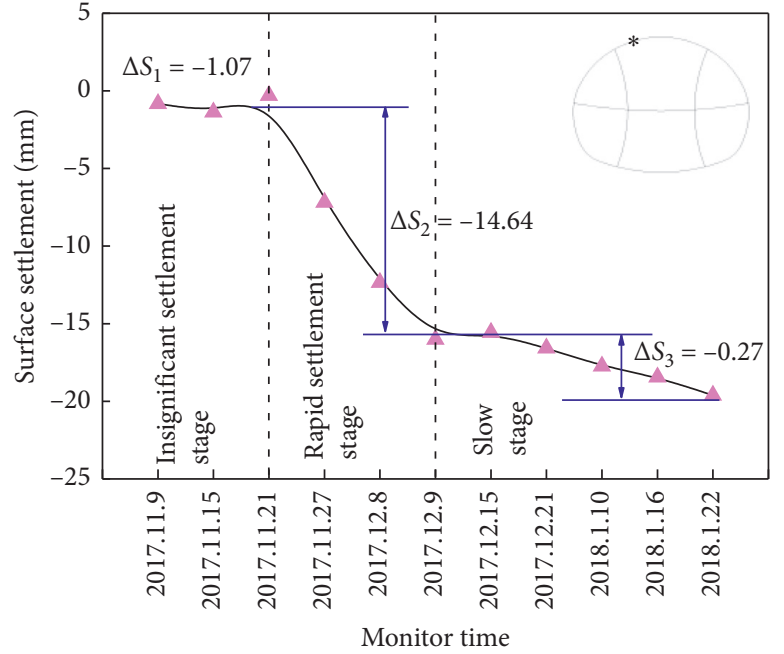

-A- Surface settlement at the centerline

(a)

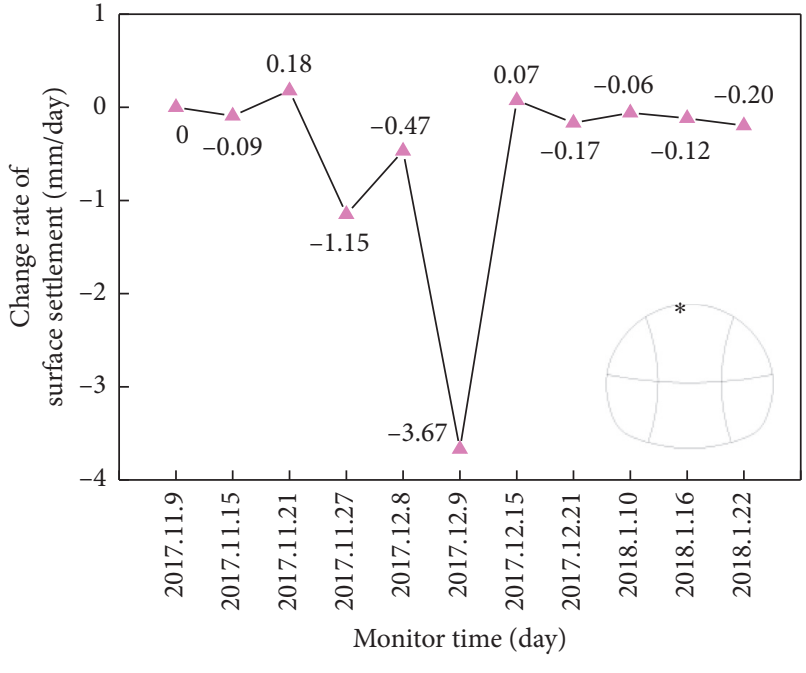

-^_ Change rate of surface settlement

(b)

FIGURE 17: Variation characteristics of the time-history curve of surface settlement. (a) Time-history curve of surface settlement. (b) Change rate of surface settlement.

the insignificant settlement stage, the settlement value of the rapid settlement stage increased by $13.57 \mathrm{~mm}$. On 9 December 2017, the change rate of tunnel surface settlement reaches a maximum of $3.67 \mathrm{~mm} /$ day as shown in Figure 17 (b), but the value is obviously less than $4.00 \mathrm{~mm} /$ day as shown in Table 2, indicating that surface settlement and its change rate still meet the requirements for tunnel safe construction.

Combining Figures 17(a) and 17(b), it can be found that when all the restraints of the tunnel face to the monitored section are released and the initial liner supporting is gradually formed, the time-history curve of surface settlement tends to stabilize with subsidence of $16.01 \sim 19.61 \mathrm{~mm}$, and the change rate gradually approaches zero (0.07 0.20 mm/day).

4.2.2. Vault Settlement Characteristics. The settlement of tunnel vault is an important indicator for monitoring the longitudinal deformation, controlling the stable state of surrounding rock, and ensuring the safe construction of the tunnel, especially in shallow-buried loess tunnel $[33,38]$. In order to directly reflect the vault deformation by testing the time-history curve of vault settlement, monitoring points 1 , 2 , and 3 are, respectively, set on the tunnel vault to monitor the vault settlement characteristics. Furthermore, the tunnel stability is evaluated, the development trend of the later vault deformation is predicted, and the construction time of the second liner is determined, based on the monitoring data.

Figure 18 shows the time-history curve of vault settlement and corresponding time-history curve of change rate. $R_{\mathrm{Si}}$ represents the change rate of vault settlement ( $\mathrm{mm} /$ day) and $T$ represents monitor time (day). It can be seen from Figure 18(a) that time-history curves of vault settlement at monitoring points 1 and 3 have gone through a rapid settlement stage, then a transitional settlement stage, and finally a stable stage, and their change trends are similar to the surface settlement law at tunnel centerline as shown in Figure 17(a). Since the soil stress at monitoring point 2 has not been released in the early excavation stage, no significant settlement of vault has occurred at this time, thus resulting in the rapid settlement stage of settlement time-history curve at monitoring point 2 lagging behind monitoring points 1 and 3. Simultaneity, this also causes the transitional settlement stage of monitoring point 2 to be significantly shortened. The vault settlement characteristics are analyzed as follows combined with the monitoring data.

In the rapid settlement stage, the vault settlement $(0.14 \sim 23.23 \mathrm{~mm})$ of monitoring point 1 (cavern (1)) is significantly larger than that of monitoring point 3 (cavern (2)) $(0.10 \sim 22.68 \mathrm{~mm})$. The maximum change rates of vault settlement at monitoring points 1 and 3 are 3.56 and $4.52 \mathrm{~mm} /$ day, respectively, which are $71.20 \%$ and $90.40 \%$ of the maximum allowable change rate shown in Table 2. It shows that settlement and deformation of tunnel vault are in a safety construction state. However, since monitoring points 1 and 2 have a relatively larger settlement and deformation in the early excavation stage, the initial supporting should be implemented and settlement monitoring should be strengthened.

With the timely construction of the supporting structure, the change rates of vault settlement at the monitoring points 1 and 3 are significantly reduced, ranging from 0.04 to $0.83 \mathrm{~mm} /$ day. The vault settlement is increased from 23.23 to $27.82 \mathrm{~mm}$, only increasing by $19.67 \%$. The time-history curves of vault settlement gradually enter the transitional settlement stage as shown in Figure 18(a).

After 32 days of monitoring, the tunnel vault of the CK9 + 415 section no longer has a large settlement, and the 


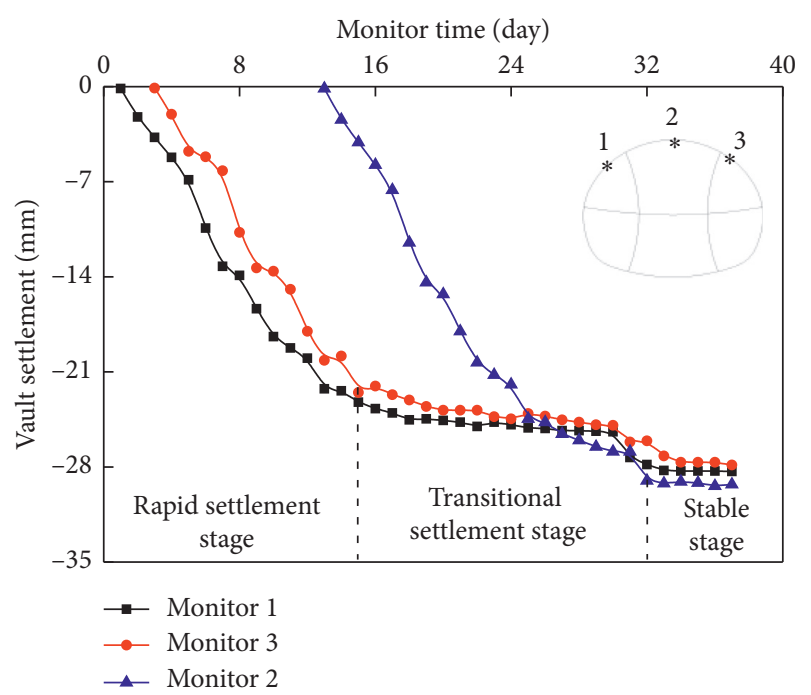

(a)

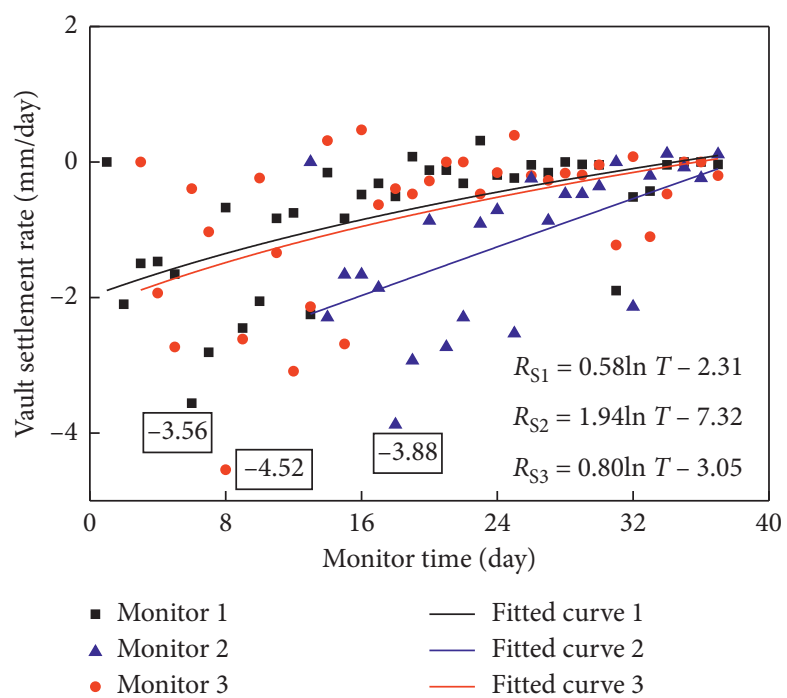

(b)

Figure 18: Vault settlement characteristics. (a) Time-history curves of vault settlement. (b) Time-history curves of the change rate of vault settlement.

time-history curve enters a stable stage. The vault settlement values of monitoring points 1,2 , and 3 are $27.82 \sim 28.30 \mathrm{~mm}$, $29.00 \sim 29.20 \mathrm{~mm}$, and $26.08 \sim 28.30 \mathrm{~mm}$, respectively. The maximum vault settlements are about $70.75 \%, 73.00 \%$, and $70.73 \%$ of the maximum allowable value $(40 \mathrm{~mm})$, respectively. The maximum allowable change rate in the stable stage gradually tends to zero, showing that the surrounding rock cavern is in a stable state.

In order to characterize the time-dependent characteristics of tunnel vault settlement, the numerical regression analysis is carried out on the relationship between the change rate of vault settlement and monitoring time. The change rate of vault settlement has a logarithmic function relationship with monitoring time, as shown in Figure 18(b).

\subsubsection{Horizontal Deformation and Convergence} Characteristics. In order to study the stability of surrounding rock and supporting, four convergence meters are installed on the excavation faces of caverns (5), (6), (7), and (8) to monitor the horizontal deformation and convergence characteristics. The measuring principle is to connect the two ends of convergence meters to a fixed measuring point, tension the steel tape with constant stress, and measure the distance between the two points with a dial indicator. The difference between the two measurements is the horizontal deformation value (horizontal displacement) during the period $[17,37]$. Then, according to horizontal deformation and its convergence condition, section deformation form, the stability of excavated rock mass and the design and construction method of initial support are judged properly $[4,17,34]$.

Combined with monitoring data, Figure 19 shows the time-history curves of horizontal deformation of caverns (5), (6), (7), and (8), and tunnel horizontal deformation rate. $R_{c i}$ represents the convergence rate $(\mathrm{mm} /$ day) and $T$ represents the monitor time (day). It is can be seen that the overall trend of horizontal deformation is consistent, which can be divided into a rapid deformation stage and a horizontal convergence stage. The following important conclusions can be drawn from Figure 19(a).

(1) Since the initial support has not been completed at the early excavation stage, the time-history curves of caverns (5) and (6) undergo a rapid deformation within 1 14 days with a horizontal deformation of $0 \sim 12.12 \mathrm{~mm}$. After the support is constructed, horizontal deformation of caverns (5) and (6) gradually enters the convergence stage. The horizontal deformation is gradually stabilized after 25 days, and the corresponding maximum horizontal convergence value is $12.90 \sim 13.10 \mathrm{~mm}$.

(2) Compared with caverns (5) and (6), the excavation time of caverns (7) and (8) is relatively late. Affected by the bearing effect of supporting structure, the time-history curves of horizontal deformation undergone a slow excessive deformation stage before entering the convergence stage. The time-history of the excessive deformation stage is 17 25 days.

(3) The horizontal deformation in the rapid deformation stage of caverns (7) and (8) is $0 \sim 10 \mathrm{~mm}$, and the maximum horizontal deformation is $82.51 \%$ of caverns (5) and (6). The horizontal deformation in the convergence stage is $12.12 \sim 12.51 \mathrm{~mm}$, and the maximum horizontal deformation is $95.49 \%$ of caverns (5) and (6).

(4) The maximum horizontal convergence values of caverns (5), (6), (7), and (8) are 13.10, 12.90, 12.51, and $12.12 \mathrm{~mm}$, respectively, which are $65.50 \%, 63.00 \%$, 

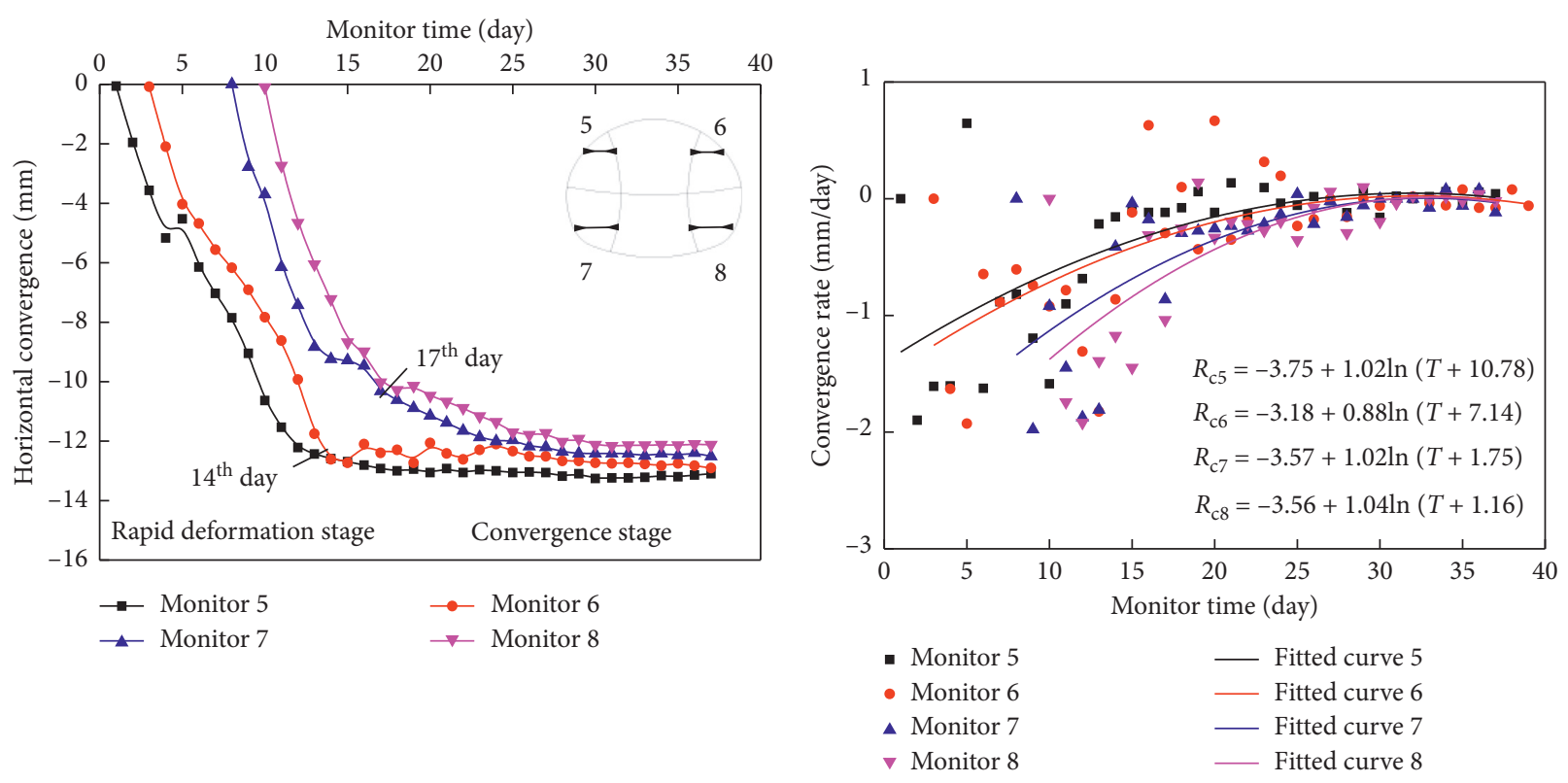

(a)

(b)

FIgURE 19: Horizontal deformation and convergence characteristics. (a) Time-history curve of horizontal deformation. (b) Time-history curve of deformation rate of horizontal convergent.

$62.55 \%$, and $60.60 \%$ of the maximum allowable deformation value $(20 \mathrm{~mm})$. From the above analysis, it can be concluded that horizontal deformation and convergence characteristics of excavated surrounding rock meet the requirements of safe construction.

Moreover, from the time-history curves of deformation rate of horizontal convergent shown in Figure 19(b), it can be seen that the change rate of the horizontal deformation in the rapid deformation stage is relatively discrete. The change rate of horizontal deformation ranges from -1.98 to $0.65 \mathrm{~mm} / \mathrm{day}$, and its maximum deformation rate $(1.98 \mathrm{~mm} /$ day $)$ is obviously less than the maximum allowable value ( $2 \mathrm{~mm} /$ day) shown in Table 2 . It can be seen that the horizontal deformation rate of the tunnel can meet the stability requirements of the surrounding rock. The change rate of horizontal deformation in the convergence stage varies from 0.08 to $0.12 \mathrm{~mm} /$ day, gradually approaching zero. Regression analysis shows that the convergence rate of horizontal convergence changes in a logarithmic function with increasing monitor time, which is similar to the development trend of the change rate of tunnel vault settlement.

Based on the above numerical analysis and on-site monitoring data, it can be seen that according to the «Code for Monitoring Measurement of Urban Rail Transit Engineering》 (GB50911-2013) [33], the surface settlement rate reaches $4 \mathrm{~mm} /$ day, vault settlement rate reaches $5 \mathrm{~mm} / \mathrm{d}$, and horizontal convergence rate reaches $2 \mathrm{~mm} / \mathrm{d}$ as control node for surrounding rock stability which can effectively guarantee the safe construction and effectively control the construction efficiency. Simultaneously, the on-site monitoring results also show that the optimization of actual construction parameters by Midas numerical model can guide the excavation of engineering rock mass and has the predictive and reference significance for the uncertainty of surface settlement, vault deformation, and bearing capacity of supporting structure.

However, by comparing the on-site monitoring data with numerical simulation data, it is found that surface settlement, vault settlement, and horizontal deformation of on-site construction monitoring have a certain discrete degree with the results obtained by Midas numerical model, which is related to the complexity of surrounding rock environment $[34,37]$. The main reason for the analysis is that in the numerical simulation of small distance tunnels, it is usually assumed that rock mass is a continuous medium under ideal conditions, and model material is an isotropic elastomer [40, 41], which is different from the discontinuity in actual engineering. The anisotropic rock-soil medium is not completely consistent. In addition, the pores and in situ stresses in rock mass and soil are ignored in the numerical simulation process, resulting in a certain gap between simulation results and on-site monitoring data [36]. However, based on the analysis of later monitoring results, it can be concluded that this difference does not affect the settlement, deformation laws of rock mass, and safe construction of the tunnel.

\section{Conclusions}

(1) The numerical simulation results show that the influence of excavation face distance on the surface settlement, vault settlement, and horizontal deformation is consistent. The surface settlement mainly occurs in the range of $-20 \sim 20 \mathrm{~m}$ from tunnel 
centerline, the maximum surface settlement occurs on the right side of tunnel centerline, and settlement trough formed has an asymmetric characteristic. The vault settlement and horizontal deformation undergoes first a rapid settlement (rapid deformation) and then a slow settlement (gradual convergence).

(2) The excavation effect of the rear cavern has no significant effect on stress and deformation of supporting structure, due to timely supporting construction and closed loop of the double-sides heading method. The connection between the initial supporting and middle partition is mainly tensile stress, and the middle and bottom parts of the supporting structure are mainly compressive stress.

(3) To ensure the tunnel stability and effectively shorten the construction period, recommendations based on numerical simulation results that the optimal excavation faces distance of $L_{1}, L_{2}$, and $L_{3}$ can be 4,9 , and $9 \mathrm{~m}$, respectively.

(4) The double-sides heading method has a significant effect on the surface settlement, vault settlement, and horizontal deformation. The surface settlement obviously occurs within the range of $-17 \sim 6 \mathrm{~m}$ from the tunnel centerline. The maximum surface settlement and change rate are $65.37 \%$ and $91.75 \%$ of the maximum allowable. The maximum vault settlement and the horizontal deformation are $73.00 \%$ and $65.50 \%$ of the maximum allowable, and its maximum change rates are $90.40 \%$ and $99.00 \%$ of the maximum allowable.

\section{Data Availability}

The data used to support the findings of this study are available from the corresponding author upon request.

\section{Conflicts of Interest}

The authors declare that they have no conflicts of interest.

\section{Acknowledgments}

The authors would like to thank the Innovation Capacity Support Plan of Shaanxi Province (2020TD-005), Project Foundation of Department of Housing and Urban Rural Development of Shaanxi Province (2019-K39), and the Natural Science Basic Research Program of Shaanxi (2019JQ-762).

\section{References}

[1] X. X. Tian, Z. P. Song, and J. B. Wang, "Study on the propagation law of tunnel blasting vibration in stratum and blasting vibration reduction technology," Soil Dynamics and Earthquake Engineering, vol. 1261, 12, pages Article ID 105813, 2019.

[2] Z. P. Song, Y. Cheng, X. X. Tian, J. B. Wang, and T. T. Yang, "Mechanical properties of limestone from Maixi tunnel under hydro-mechanical coupling," Arabian Journal of Geosciences, vol. 13, no. 402, pp. 1-13, 2020.
[3] N. F. Liu, N. Li, C. B. Xu, G. Li, Z. P. Song, and M. Yang, "Mechanism of secondary lining cracking and its simulation for the Dugongling tunnel," Rock Mechanics and Rock Engineering, vol. 53, no. 10, pp. 4539-4558, 2020.

[4] Z. P. Song, G. L. Shi, B. Y. Zhao, K. Zhao, and J. B. Wang, "Study of the stability of tunnel construction based on doubleheading advance construction method," Advances in Mechanical Engineering, vol. 12, no. 1, pp. 1-17, 2020.

[5] R. H. Mai, S. Li, W. B. Li, and G. Chen, "Analysis of antioverturn stability of curved beam bridge considering earthquake effects," Journal of Jiangxi University of Technology, vol. 41 , no. 3 , pp. 9-15, 2020.

[6] D. F. Xia, "Impact analysis of excavated tunnel undercrossing on south-to-north water transfer project," Journal of Jiangxi University of Technology, vol. 41, no. 3, pp. 24-30, 2020.

[7] K. Zhao, T. Y. Teng, P. Zeng, and W. J. Xie, "Experimental study on acoustic emission characteristics of red sandstone under uniaxial compression with different water content," Journal of Jiangxi University of Technology, vol. 40, no. 5, pp. 1-7, 2019.

[8] C. F. Zhou, "Analysis and protective measures of city wall due to underneath crossing shield tunnel," Journal of Jiangxi University of Technology, vol. 40, no. 5, pp. 31-36, 2019.

[9] G. Deng, H. W. Zhu, J. Zhou, R. Z. Xiao, and S. H. Wang, "Modification of Peck formula based on construction of Guangzhou metro tunnel," Journal of Jiangxi University of Technology, vol. 40, no. 3, pp. 9-13, 2019.

[10] Q. Yin, Q. Liu, and S. He, "Analysis of stability and long term damage law of the flathead shaped excavated coal measure soil slope," Journal of Jiangxi University of Technology, vol. 40, no. 1, pp. 68-73, 2019.

[11] P. Z. Zhu, H. Jiang, Z. Qin, F. Q. Lin, W. F. Shi, and W. He, "Static and dynamic loading effects on the stability of a tailings pond under expansion construction," Journal of Jiangxi University of Technology, vol. 40, no. 1, pp. 62-67, 2019.

[12] K. H. Jiang, Z. K. Yue, Z. Zhou, H. Zhu, D. D. Gao, and T. L. Wang, "Field test on influence of side-crossing shield tunnel construction on adjacent high speed railway bridge pile foundation," Journal of Jiangxi University of Technology, vol. 39 , no. 5 , pp. 1-8, 2018.

[13] M. Wang, S. M. Liao, and X. Y. Hou, "Ground deformation prediction of shield tunnelling in closely overlapped subway tunnel construction," Journal of Tongji University (Natural Science), vol. 32, no. 9, pp. 1141-1146, 2004.

[14] Z. L. Niu, C. P. Liu, L. Zheng et al., "Numerical simulation study on excavation and support of slab tunnel in large section highway," Journal of Xi'an University of Architecture and Technology, vol. 52, no. 3, pp. 376-403, 2020.

[15] J. Guo, "Analysis on construction safety of optimized double side drift method," Tunnel Construction, vol. 34, no. 6, pp. 525-533, 2014.

[16] X. R. Liu, H. Sun, X. J. Chen, and Y. S. Huang, "Numerical analysis on mid-partition structure of the loess double arch tunnel," Chinese Journal of Underground Space and Engineering, vol. 1, no. 6, pp. 837-840, 2005.

[17] Z. L. Zhong, X. R. Liu, F. Yuan, and W. B. Qu, "Effect of excavation length of inverted arch in one step on stability of multi-arch tunnels in loess," Chinese Journal of Geotechnical Engineering, vol. 30, no. 3, pp. 462-466, 2008.

[18] X. M. Gou and J. R. Zhang, "Study on strength and consolidation mechanical properties of intact unsaturated cohesive loess," Modern Tunnelling Technology, vol. 55, no. z2, pp. 217-222, 2018. 
[19] G. H. Zhang, L. B. Chen, S. X. Qian, G. Y. Cai, C. F. Wu, and Q. Li, "On-site supervision measure and analysis of Damaoshan tunnels with large section and small clear-distance," Rock and Soil Mechanics, vol. 31, no. 2, pp. 489-496, 2010.

[20] Z. Y. Sun, D. L. Zhang, Q. Fang, and W. Su, "Distribution of surrounding rock pressure of shallow highway tunnels with small spacing," China Journal of Highway and Transport, vol. 31, pp. 84-94, 2018.

[21] X. S. Hao, L. Jin, and Y. K. He, "Highway tunnel construction optimization of double-sidewalls guiding-hole method," Modern Transportation Technology, vol. 1, pp. 61-64, 2008.

[22] J. Ghaboussi and R. E. Ranken, "Interaction between two parallel tunnels," International Journal for Numerical and Analytical Methods in Geomechanics, vol. 1, no. 1, pp. 75-103, 1977.

[23] C. W. Ng, K. M. Lee, and D. K. Tang, "Three-dimensional numerical investigations of new Austrian tunnelling method (NATM) twin tunnel interactions," Canadian Geotechnical Journal, vol. 41, no. 3, pp. 523-539, 2004.

[24] S. H. Park and T. Adachi, "Laboratory model tests and FE analyses on tunneling in the unconsolidated ground with inclined layers," Tunnelling and Underground Space Technology, vol. 17, no. 2, pp. 181-193, 2002.

[25] K. M. Lee and R. K. Rowe, "Finite element modelling of the three-dimensional ground deformations due to tunnelling in soft cohesive soils: part I-method of analysis," Computers and Geotechnics, vol. 10, no. 2, pp. 87-109, 1990.

[26] B. L. Chu, S. C. Hsu, Y. L. Chang, and Y. S. Lin, "Mechanical behavior of a twin-tunnel in multi-layered formations," Tunneling and Underground Space Technology, vol. 22, no. 3, pp. 351-362, 2006.

[27] S. Suwansawat and H. H. Einstein, "Describing settlement troughs over twin tunnels using a superposition technique," Journal of Geotechnical and Geoenvironmental Engineering, vol. 133, no. 4, pp. 445-468, 2007.

[28] J. N. Shirlaw, S. Doran, and B. Benjamin, "A case study of two tunnels driven in the Singapore 'Boulder Bed' and in grouted coral sands," Geological Society, London, Engineering Geology Special Publications, vol. 5, no. 1, pp. 93-103, 1988.

[29] E. J. Cording, "Displacements around soft ground tunnels," in Proceedings of the 5th Pan American Conference on Soil Mechanics and Foundation Engineering, pp. 517-632, Buenos Aires, Argentina, November 1975.

[30] Y. Cheng, Z. P. Song, J. F. Jin, and T. T. Yang, "Attenuation characteristics of stress wave peak in sandstone subjected to different axial stresses," Advances in Materials Science and Engineering, vol. 2019, Article ID 6320601, 11 pages, 2019.

[31] Y. W. Zhang, Z. P. Song, and X. L. Weng, "A constitutive model for loess considering the characteristics of structurality and anisotropy," Soil Mechanics and Foundation Engineering, vol. 57, 2020, In press.

[32] Y. Cheng, Z. P. Song, J. F. Jin, and J. B. Wang, "Experimental study on stress wave attenuation and energy dissipation of sandstone under full deformation condition," Arabian Journal of Geosciences, vol. 12, no. 3, pp. 736-750, 2019.

[33] Z. P. Song, X. X. Tian, Q. Liu, Y. Zhang, and G. Zhou, "Numerical analysis and application of the construction method for small interval tunnel in the turn line of metro," Science Progress, vol. 103, no. 3, 25 pages, 2020.

[34] Z. P. Song, J. C. Mao, X. X. Tian, Y. W. Zhang, and J. B. Wang, "Optimization analysis of controlled blasting for passing through houses at close range in super-large section tunnels," Shock and Vibration, vol. 2019, Article ID 1941436, 16 pages, 2019.
[35] Y. Cheng, Z. P. Song, J. F. Jin, and T. T. Yang, "Waveform characterization and energy dissipation of stress wave based on modified SHPB tests," Geomechanics and Engineering, vol. 22, no. 2, pp. 187-196, 2020.

[36] Y. M. Zhang, W. J. Li, and J. C. Li, "Numerical simulation of depth bias overwhelming force tunnel construction," Mechanics in Engineering, vol. 33, no. 2, pp. 46-51, 2011.

[37] J. S. Xu, Q. Z. Lu, and H. Y. Fu, "Ground fissures along Xi'an subway line 4: hazard analysis and countermeasures," The Chinese Journal of Geological Hazard and Control, vol. 23, no. 1, pp. 76-82, 2012.

[38] F. G. Jiang, L. L. Bai, M. Song, L. T. Wang, and X. T. Tan, "Analysis on construction stability of large section tunnel of Harbin City Metro," Journal of Jilin University (Engineering and Technology Edition), vol. 50, no. 4, pp. 1419-1427, 2020.

[39] K. Wu and Z. S. Shao, "Visco-elastic analysis on the effect of flexible layer on mechanical behavior of tunnels," International Journal of Applied Mechanics, vol. 11, no. 3, Article ID 1950027, pp. 1-15, 2019.

[40] X. X. Kong, C. C. Xia, Y. L. Qiu, L. Y. Zhang, and J. W. Gong, "Study of construction mechanical behavior of parallel-small spacing metro tunnels excavated by shield method and cross diaphragm (CRD) method in loess region," Rock and Soil Mechanics, vol. 32, no. 2, pp. 516-524, 2011.

[41] K. Wu, Z. S. Shao, S. Qin, and B. Li, "Determination of deformation mechanism and countermeasures in silty clay tunnel," Journal of Performance of Constructed Facilities, vol. 34, no. 1, pp. 1-15, Article ID 04019095, 2019. 